Int. J. Dev. Biol. 61: 697-722 (2017)

doi: $10.1387 / \mathrm{ijdb} .170202 \mathrm{sb}$

\title{
Developmental cell-cell communication pathways in the cephalochordate amphioxus: actors and functions
}

\author{
STEPHANIE BERTRAND*,1, YANN LE PETILLON ${ }^{1}$, ILDIKÓ M.L. SOMORJAI ${ }^{2,3}$ and HECTOR ESCRIVA*,1 \\ 'Sorbonne Universités, UPMC Univ Paris 06, CNRS, Biologie Intégrative des Organismes Marins (BIOM), \\ Observatoire Océanologique, Banyuls/Mer, France, ${ }^{2}$ Gatty Marine Laboratory, Scottish Oceans Institute, East Sands, \\ University of St Andrews, St Andrews, Scotland, UK and ${ }^{3}$ Biomedical Sciences Research Complex, North Haugh, \\ University of St Andrews, St Andrews, Scotland, UK
}

\begin{abstract}
During embryonic development, cells of metazoan embryos need to communicate in order to construct the correct bodyplan. To do so, they use several signals that usually act through interactions between ligands and receptors. Interestingly, only a few pathways are known to be fundamental during animal development, and they are usually found in all the major metazoan clades, raising the following question: how have evolution of the actors and of the functions of these pathways participated in the appearance of the current diversity of animal morphologies? The chordate lineage comprises vertebrates, their sister group the urochordates, and the cephalochordates (i.e. amphioxus). Urochordates are quite derived relative to the chordate ancestor, whereas cephalochordates and vertebrates share many morphological traits. Thus, comparing embryonic development between vertebrates and cephalochordates should give us some insight into the ancestral characters present in chordates and into the morphological evolution in this clade. However, while much is known about the function of different signalling pathways in vertebrates, data are still scarce in the literature for cephalochordates. In this review, we summarize the current state of the field concerning the expression of actors and the function of the major cell-cell communication pathways, including Hedgehog (Hh), Notch, Nuclear Receptor (NR), Receptor Tyrosine Kinase (RTK), Transforming Growth Factor- $\beta$ (TGF- $\beta$ ) and Wingless/Int (Wnt), in amphioxus.
\end{abstract}

KEY WORDS: chordates, evolution, development, signalling pathways

\section{Introduction}

Vertebrates belong to the chordate group together with the urochordates, their sister group, and the cephalochordates (i.e. amphioxus). Although urochordates are more closely related to vertebrates, they show derived features making difficult theinference of ancestral characters by comparing their traits with those of the other clades (Delsuc et al., 2006). On the other hand, amphioxus seem to have retained many ancestral chordate characters at both developmental and genomic levels, making these small marine animals a good model for chordate evo-devo studies (Bertrand and Escriva, 2011). Most cephalochordates live in the sand in shallow waters and are filter feeders. They are gonochoric, and reproduction occurs through external fertilization in the sea water column after males and females have released their gametes at sunset
(Bertrand and Escriva, 2011). The transparent zygote divides to form a morula, and then a blastula consisting of a single cell layer surrounding a cavity, the blastocoel (Conklin, 1932, Hatschek, 1893, Holland and Holland, 2007, Kowalevsky, 1867). The vegetal region flattens and forms the vegetal plate, which will invaginate to form a gastrula with two germ layers. The external layer, the ectoderm, will develop to form both the epidermis on the ventral side, and the neural plate in the dorsal region (Fig. 1). The mesendoderm is the internal layer. Its axial dorsal region is fated to become the

\footnotetext{
Abbreviations used in this paper: $\mathrm{EPH}$, erythropoietin-producing human hepatocellular receptor; FGFR, fibroblast growth factor receptor; Hh, hedgehog; INSR, insulin receptor; NR, nuclear receptor; PDGFR, platelet-derived growth factor receptor; RTK, receptor tyrosine kinase; TGF, transforming growth factor; TRK, tropomyosin receptor kinase; VEGFR, vascular endothelial growth factor receptor.
}

\footnotetext{
*Address correspondence to: Hector Escriva. BIOM, UMR7232 CNRS/UPMC, Observatoire Océanologique de Banyuls sur Mer, Avenue Pierre Favre, 66650, Banyuls sur Mer, France. Tel: +33(0)468887390. Fax: +33(0)468887393. E-mail:hescriva@obs-banyuls.fr iD http://orcid.org/0000-0001-7577-5028 or

Stéphanie Bertrand, BIOM, UMR7232 CNRS/UPMC, Observatoire Océanologique de Banyuls sur Mer, Avenue Pierre Favre, 66650, Banyuls sur Mer, France. Tel: +33(0)430192405. Fax: +33(0)468887393. E-mail:bertrand@obs-banyuls.fr (iD) http://orcid.org/0000-0002-0689-0126
}

Submitted: 13 August, 2017; Accepted: 22 September, 2017.

ISSN: Online 1696-3547, Print 0214-6282 
notochord, whereas the dorsal paraxial mesendoderm gives rise to the somites. Finally, the ventral mesendoderm will form the embryonic gut. At the end of gastrulation, the epidermis that has detached from the neural plate covers the whole embryo. During neurulation, the neural plate curves to form the neural tube, which is enlarged in the most anterior region, forming the so-called cerebral vesicle (Fig. 2). The somites start to form by enterocoely from the dorsal paraxial mesendoderm while the embryo elongates. In the late neurula stage embryo, several regions of the anterior endoderm begin to form different structures. Two diverticula are established in the most anterior region, the Hatschek's left and right diverticulum, which will later develop into the pre-oral pit and the rostral coelom, respectively. On the right side, the future club-shaped gland and the region where the first gill slit will open can be detected, whereas the endostyle starts to develop from the ventral anterior endoderm. Finally, at the larval stage, the formation of these structures is achieved and the mouth opens on the left side (Fig. 2).

Many questions remain as to how cell-cell communication mediates the processes taking place in these different developmental stages. In metazoans, few intercellular signals are known, and deciphering their specific functions in each lineage is crucial for our understanding of morphological evolution in animals. In this review, we will therefore briefly present the mode of action for the main signalling pathways (Hedgehog $(\mathrm{Hh})$, Notch, Nuclear
Receptor (NR), Receptor Tyrosine Kinase (RTK), Transforming Growth Factor- $\beta$ (TGF- $\beta$ ), Wingless/Int (Wnt) pathways), as well as describe the embryonic expression of known actors in amphioxus. We will then detail available information on the embryonic function of each signal. Table 1 summarizes the bibliography concerning gene expression patterns, whereas Table 2 presents the main results obtained using pharmacological treatments to modulate these different pathways.

\section{Hedgehog pathway}

\section{How does it work?}

The role of the Hedgehog $(\mathrm{Hh})$ signal during embryogenesis was first discovered in Drosophila. The name was derived from the phenotype of null mutants for $H h$, which presented hair-bristles resembling the spines of the hedgehog (Nusslein-Volhard and Wieschaus, 1980). This signalling pathway is very complex and requires the participation of many actors in addition to the ligands and receptors. The Hedgehog ligand proteins contain two regions. The $\mathrm{N}$-terminal region is the active peptide whereas the $\mathrm{C}$-terminal region, which shows some similarity with inteins, possesses autocatalytic activity. After autocleavage of $\mathrm{Hh}$, the $\mathrm{N}$-terminal peptide is linked to a cholesterol molecule and to a palmitic acid and is recruited at the plasma membrane. From there it can be released in different ways into the extracellular space in order to spread through tissues (Briscoe and Therond, 2013, Lee et al., 2016) (Fig. 3). The first identified receptor of $\mathrm{Hh}$ is a 12-pass transmembrane protein called Patched (Ptc), which acts as a constitutive repressor of the pathway (Hooper and Scott, 1989, Nakano et al., 1989). In the absence of $\mathrm{Hh}$, Ptc represses Smoothened (Smo), a GPCR family protein, resulting in the proteolysis of the zinc-finger domain transcription factor Gli (or Cubitus interruptus (Ci) in Drosophila), which is processed to its repressor form (Fig. 3). Following $\mathrm{Hh}$ binding to Ptc, Smo is activated and Gli translocates into the nucleus in its active form, leading to the transcription of target genes (Briscoe and Therond, 2013, Lee et al., 2016) (Fig. 3).

\section{Receptors and ligands in amphioxus}

Amphioxus possesses a unique $\mathrm{Hh}$ gene, orthologous to vertebrate Sonic, Indian and Desert Hedgehog (Shimeld, 1999). Its expression pattern has been described in three amphioxus species, Branchiostoma floridae, B. belcheri and B. lanceolatum (Shimeld, 1999, Shimeld et al., 2007, Somorjai et al., 2008, Zhang et al., 2002). Hh transcripts are first detected in the dorsal mesendoderm at the early gastrula stage (Somorjai et al., 2008, Zhang et al., 2002). As gastrulation proceeds, expression is observed in the presumptive notochord and floor plate

Fig. 1. Early embryonic development in amphioxus. Three early developmental stages are presented, from gastrula to neurula. For each, two pictures of the same fixed embryo are shown together with small schemes indicating the different presumptive, or already formed, territories/structures. Scale bar, $50 \mu \mathrm{m}$. 
TABLE 1

\section{AMPHIOXUS ACTORS OF THE DIFFERENT SIGNALLING PATHWAYS CITED IN THIS REVIEW AND REFERENCES OF ARTICLES IN WHICH THEIR EXPRESSION PATTERN HAS BEEN DESCRIBED}

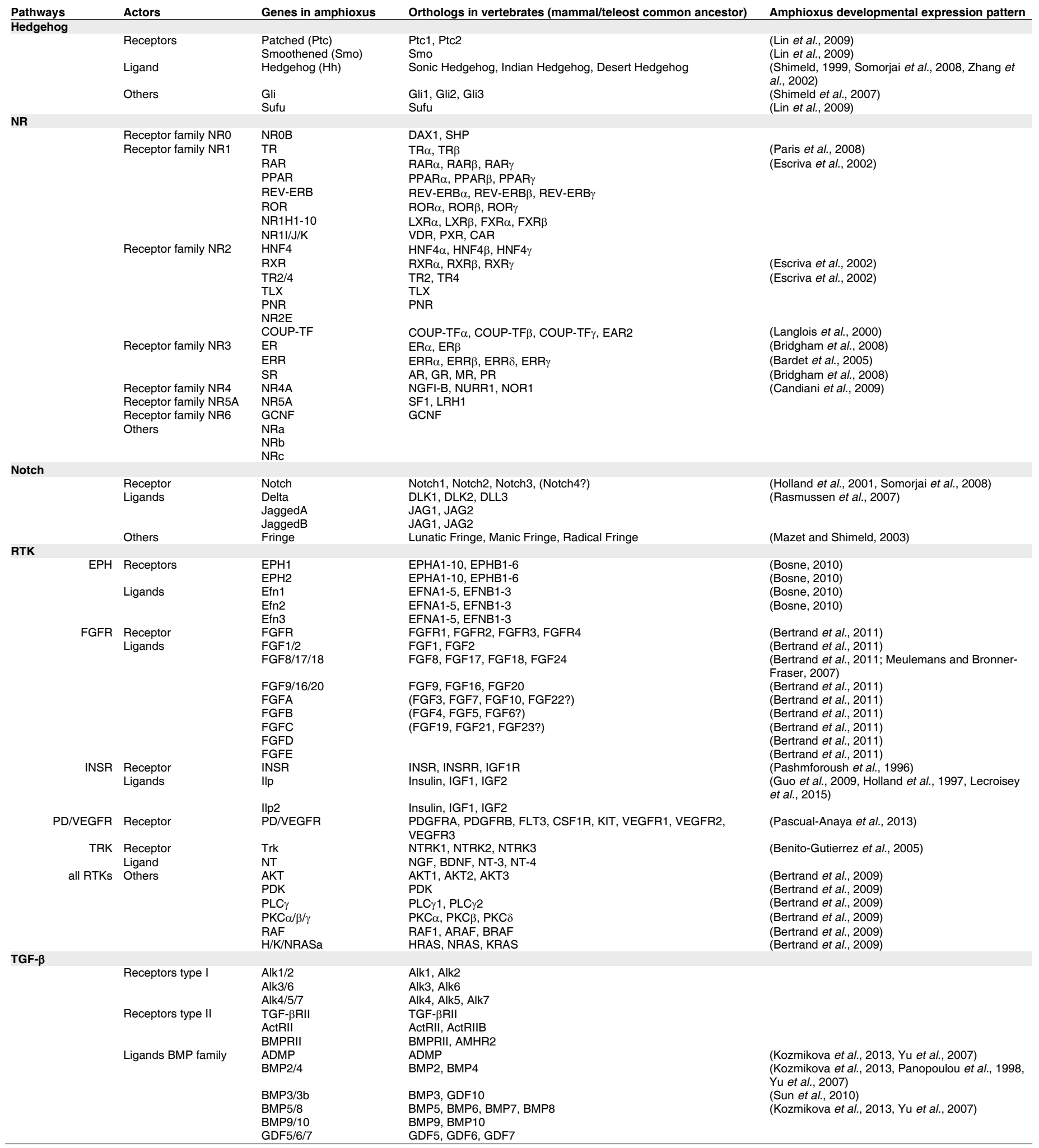


and in two endodermal regions adjacent to the paraxial mesoderm (Shimeld, 1999, Somorjai et al., 2008). In neurula stage embryos and in larvae, $\mathrm{H} h$ is expressed in the notochord, the tailbud, the endostyle and the pre-oral pit (Shimeld, 1999, Shimeld et al., 2007, Somorjai et al., 2008, Zhang et al., 2002), as well as transiently in some ventral neural tube cells (Shimeld, 1999). The expression of both Ptc, orthologous to Ptc1 and Ptc2 in vertebrates, and Smo was analyzed in B. belcheri (Lin et al., 2009). The Ptc transcripts are first detected in the dorsal region of gastrula stage embryos. In neurulae, Ptc is expressed in newly formed somites and in the anterior endoderm (Lin et al., 2009). As the embryo elongates, expression is also detected in the notochord, the presumptive gill slit and the pre-oral pit. Finally, at the larval stage, Ptc is expressed in the cerebral vesicle, the somites, the gill slits, the pre-oral pit, the club-shaped gland and in the gut and pharynx epithelium (Lin etal., 2009). Smo has a similar expression pattern. It is first expressed later than Ptc in the newly formed somites and anterior endoderm in early neurula stage embryos (Lin et al., 2009). Expression is observed at later stages in the somites, the gut and the anterior notochord (Lin et al., 2009).

\section{Other actors}

The expression of two other major players of the Hh pathway has been described in amphioxus. A single Gligene, orthologous to Gli1, 2 and 3 in vertebrates, was found in the amphioxus genome (Shimeld et al., 2007). This gene produces at least two splice variants and the presence of transcripts was first analyzed by using a probe able to recognize both (Shimeld et al., 2007). Gli expression is first detected in the dorsal ectoderm and mesendoderm of late gastrula embryos. In neurulae, Gli is expressed in the lateral neural plate and in the paraxial mesoderm, in cells alongside the Hh expressing regions. Expression then fades in these territories and is observed in the cerebral vesicle, in the Hatschek's left diverticulum and in the forming gill slits. In the larva, labelling is observed in the cerebral vesicle, the pre-oral pit, the club-shaped gland as well as in the gill slits. Using a probe only recognizing the

\section{TABLE 1 (CONTINUED)}

\section{AMPHIOXUS ACTORS OF THE DIFFERENT SIGNALLING PATHWAYS CITED IN THIS REVIEW AND REFERENCES OF ARTICLES IN WHICH THEIR EXPRESSION PATTERN HAS BEEN DESCRIBED}

\begin{tabular}{|c|c|c|c|c|}
\hline Pathways & Actors & Genes in amphioxus & Orthologs in vertebrates (mammal/teleost common ancestor) & Amphioxus developmental expression pattern \\
\hline & Ligands & Activin/Inhibin 1 & (Inhibin $\beta-A$, Inhibin $\beta-B$, Inhibin $\beta-C$, Inhibin $\beta-E$ ?) & \\
\hline & TGF $\beta /$ Nodal/Activin family & Activin/Inhibin 2 & (Inhibin $\beta-A$, Inhibin $\beta-B$, Inhibin $\beta-C$, Inhibin $\beta-E ?$ ) & \\
\hline & & Lefty & Lefty1, Lefty2 & $\begin{array}{l}\text { (Morov et al., 2016, Onai et al., 2010, Yu et al., } \\
\text { 2007) }\end{array}$ \\
\hline & & Myostatin & Myostatin, GDF11 & \\
\hline & & Nodal & Nodal & $\begin{array}{l}\text { (Morov et al., 2016, Onai et al., 2010, Yu et al., } \\
\text { 2002, Yu et al., 2007) }\end{array}$ \\
\hline & & TGF- $\beta$ & TGF- $\beta 1$, TGF- $\beta 2$, TGF- $\beta 3$ & \\
\hline & & Vg1 & GDF1 & (Onai et al., 2010) \\
\hline & Others & BAMBI & BAMBI & (Yu et al., 2007) \\
\hline & & Chordin & Chordin & (Somorjai et al., 2008, Yu et al., 2007) \\
\hline & & Cerberus & Cerberus, DAND5 & (Le Petillon et al., 2013, Onai et al., 2010) \\
\hline & & Gremlin & Gremlin1, Gremlin2 & (Le Petillon et al., 2013) \\
\hline & & NBL1 & NBL1 & (Le Petillon et al., 2013) \\
\hline & & Tolloid & BMP1, Tolloid like 1, Tolloid like 2 & (Yu et al., 2007) \\
\hline & & Tsg & Tsg & (Yu et al., 2007) \\
\hline \multicolumn{5}{|l|}{ Wnt } \\
\hline & Receptors & Frizzled 1/2/7 & Fzd1, Fzd2 & (Qian et al., 2013) \\
\hline & & Frizzled 4 & $\mathrm{Fzd} 4$ & (Qian et al., 2013) \\
\hline & & Frizzled 5/8 & Fzd5, Fzd8 & (Qian et al., 2013) \\
\hline & & Frizzled $9 / 10$ & Fzd9, Fzd10 & (Qian et al., 2013) \\
\hline & Antagonists & sFRP1/2/5 & SFRP1, SFRP2/sizzled, SFRP3/FrzB, sFRP5 & (Kong et al., 2012, Yu et al., 2007)* \\
\hline & & sFRP3/4 & sFRP4 & (Yu et al., 2007) \\
\hline & & Dkk1/2/4 & Dkk1 Dkk2, Dkk4 & (Yu et al., 2007, Zhang and Mao, 2010) \\
\hline & & Dkk3 & Dkk3 & (Yu et al., 2007, Zhang and Mao, 2010) \\
\hline & Co-Receptors & LRP5/6 & LRP5, LRP6 & (Wang et al.) \\
\hline & & $\begin{array}{l}\text { Kremen1, Kremen2, } \\
\text { Kremen3, Kremen4 }\end{array}$ & Kremen1, Kremen2 & (Zhang and Mao, 2010) \\
\hline & Ligands & Wnt1 & Wnt1 & (Holland et al., 2000) \\
\hline & & Wnt2 & Wnt2, Wnt2b/Wnt13 & (Somorjai et al., in prep) \\
\hline & & Wnt3 & Wnt3, Wnt3a & $\begin{array}{l}\text { (Albuixech-Crespo et al., 2017, Schubert et al., } \\
\text { 2001, Somorjai et al., 2008, Yu et al., 2007) }\end{array}$ \\
\hline & & Wnt4 & Wnt4 & (Schubert et al., 2000b) \\
\hline & & Wnt5 & Wnt5a, Wnt5b & $\begin{array}{l}\text { (Albuixech-Crespo et al., 2017, Schubert et al., } \\
\text { 2001, Somorjai et al., 2008, Somorjai et al., 2012) }\end{array}$ \\
\hline & & Wnt6 & Wnt6 & (Schubert et al., 2001, Somorjai et al., 2008) \\
\hline & & Wnt7 & Wnt7a, Wnt7b & $\begin{array}{l}\text { (Albuixech-Crespo et al., 2017, Schubert et al., } \\
\text { 2000b, Somorjai et al., 2008) }\end{array}$ \\
\hline & & Wnt8 & Wnt8a, Wnt8b & $\begin{array}{l}\text { (Albuixech-Crespo et al., 2017, Morov et al., 2016, } \\
\text { Schubert et al., 2000c, Yu et al., 2007) }\end{array}$ \\
\hline & & Wnt9 & Wnt9a, Wnt9b & (Somorjai et al., in prep) \\
\hline & & Wnt10 & Wnt10a, Wnt10b & (Somorjai et al., in prep) \\
\hline & & Wnt11 & Wnt11 & (Schubert et al., 2000a, Yu et al., 2007) \\
\hline & & Wnt16 & Wnt16 & (Somorjai et al., in prep) \\
\hline & Others & Dsh & Dvl1, Dvl2, Dvl3 & (Wang et al., 2016) \\
\hline & & Axin & Axin1, Axin2 & (Beaster-Jones et al., 2008, Wang et al., 2016) \\
\hline & & GSK3 $\beta$ & GSK3 $\beta$ & (Wang et al., 2016) \\
\hline & & $\beta$-catenin & $\beta$-catenin, Plakoglobin & \\
\hline & & TCF & TCF1, TCF3, TCF4, LEF1 & (Lin et al., 2006) \\
\hline & & CK1 $1 \alpha$ & $\mathrm{CK} 1 \alpha$ & (Wang et al., 2016) \\
\hline & & CK1 $1 \delta$ & CK1 $1 \delta$ & (Wang et al., 2016) \\
\hline & & Groucho & Groucho & (Wang et al., 2016) \\
\hline & & APC & APC & (Wang et al., 2016) \\
\hline
\end{tabular}



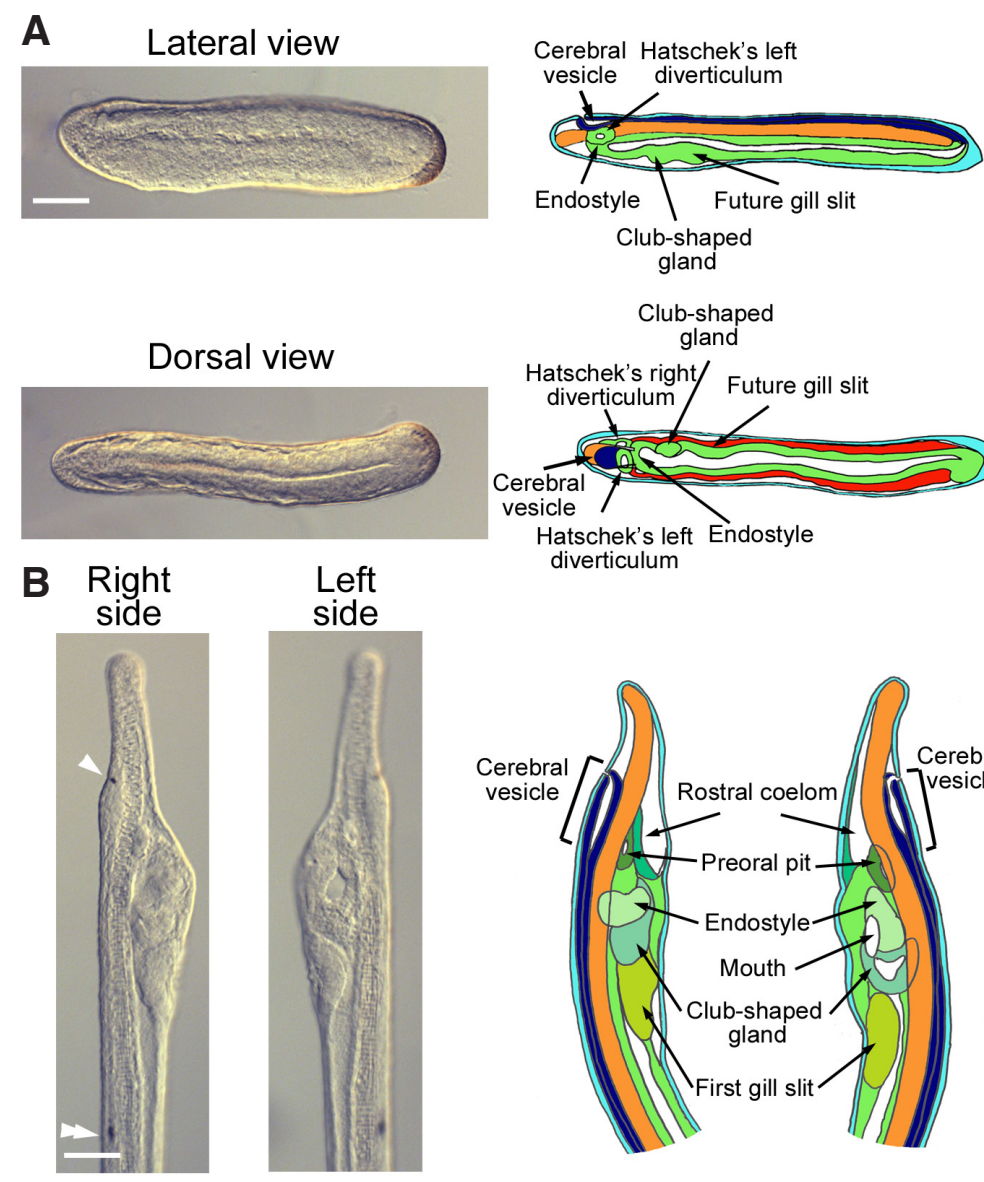

\section{Dorsal view}

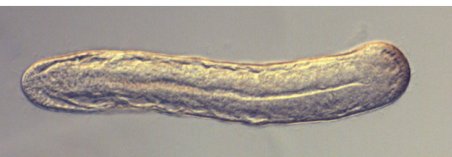

Left side
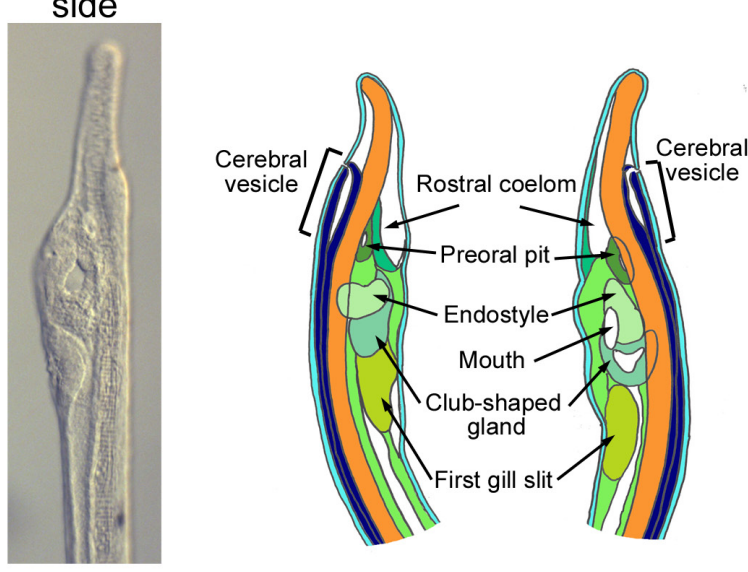

Fig. 2. Late embryonic development in amphioxus. (A) Pictures of lateral and dorsal view of the same late neurula stage embryo are shown together with small schemes presenting the different presumptive structures that are found in the anterior region. Scale bar, 50 $\mathrm{\mu m}$. (B) Pictures of the anterior region of a larva on its left and right side are shown together with schemes highlighting the different pharyngeal structures that are formed at this stage. The frontal eye is indicated by a white arrowhead and the first pigment spot by a double arrowhead. Scale bar, $50 \mu \mathrm{m}$. Colour code is according to Fig. 1.

large splicing isoform, the authors showed that it is present only in neurulating embryos in the somitic mesoderm and in the neural plate (Shimeld et al., 2007).

Another actor for which embryonic expression has been described is Sufu (Suppressor of Fused homolog). Sufu is a negative regulator of $\mathrm{Hh}$ signalling (Fig. 1). It binds to Gli or $\mathrm{Ci}$ and impedes its translocation into the nucleus (Briscoe and Therond, 2013, Lee et al., 2016). In B. belcheri, Sufu is expressed in the same regions as Smo (Lin et al., 2009).

\section{Functional studies}

Amphioxus mutants for the $H$ h gene were generated using TALEN (Wang et al., 2015). 25\% of the F1 embryos showed deformities with a curled tail, no mouth and a ventral endostyle and gill slits, suggesting a role of $\mathrm{Hh}$ pathway in the control of $L / R$ asymmetry in amphioxus (Wang et al., 2015). Purmorphamine (Sinha and Chen, 2006) and Cyclopamine (Chen et al., 2002) are molecules that are known to activate and inhibit the Hh pathway, respectively, by interacting with Smo. However, up to now there is no study report- ing the effects of such molecules in amphioxus.

Functional studies have been undertaken in heterologous assays to test for the activity of the two Gli isoforms. Using different approaches such as mammalian cell transfection, chick neural tube electroporation and expression of both isoforms in Drosophila imaginal discs, the authors showed that the long isoform is an activator of $\mathrm{Hh}$ signalling, whereas the small isoform acts as a repressor (Shimeld et al., 2007).

\section{Notch pathway}

\section{How does it work?}

The first Notch gene sequence was described in the 80's in Drosophila (Kidd et al., 1986, Wharton et al., 1985). The Notch receptor is a one-pass transmembrane protein with extracellular EGF repeats, LIN-12-Notch repeats (LNR) and an intracellular specific domain called NICD (Notch IntraCellular Domain) containing a RBP-jk association module (RAM), nuclear localization signals, ankyrin repeats and PEST motifs (proline, glutamic acid, serine, threonine) (Wang, 2011). Canonical ligands of Notch are likewise transmembrane proteins forming the Delta/Serrate/lag-2 (DSL) family, which also present EGF repeats in their extracellular region as well as a conserved so-called DSL domain (Wang, 2011). The fact that both receptors and ligands are transmembrane proteins implies that the Notch signal can only be achieved between contacting cells. Following ligand binding, the Notch receptor is first cleaved by metalloproteases releasing the ectodomain, and then by a $\gamma$-secretase complex that frees the NICD, which can translocate into the cell nucleus and interact with the DNA-binding protein CSL (CBF1/RBPjk/Su(H)/Lag-1) (Kopan and llagan, 2009) (Fig. 4). Together, NICD and CSL recruit the coactivator Mastermind/Lag-3, leading to transcriptional activation of target genes (Kopan and llagan, 2009) (Fig. 4). Although a panel of genes coding for regulators of the Notch pathway exists in the amphioxus genome (Gazave et al., 2009), we will mainly focus our attention on genes for which expression patterns have been described.

\section{Receptors and ligands in amphioxus}

In vertebrates, four receptors are known, at least in mammals. In amphioxus, one Notch receptor gene has been described in $B$. floridae, which is orthologous to vertebrate Notch 1/2/3/4 (Holland et al., 2001). The Notch protein contains 36 EGF repeats, 3 LNR, a transmembrane region, a RAM domain, 6 ankyrin repeats and several sites for proteolytic cleavage, which are required for Notch signalling pathway activation. Transcripts are first detected by in situ hybridization at the gastrula stage, in a ring of presumptive mesendoderm (Holland et al., 2001). Subsequently, a gradient in the dorsal mesendoderm is observed with higher expression in the posterior region (Holland et al., 2001). In the neurulating embryo, strong Notch expression is detected in the posterior mesoderm and in the dorsal part of the three most anterior somites (Holland et al., 2001). While the embryo is elongating, Notch transcripts are expressed in the second-youngest somites and in the neural plate and forming notochord (Holland et al., 2001). Thereafter, expression in the somites gets more intense in their posterior part, and becomes stronger in the forming neural tube (Holland et al., 2001). 
TABLE 2

\section{SUMMARY OF PHENOTYPES OBTAINED AFTER PHARMACOLOGICAL TREATMENTS INTERFERING WITH DIFFERENT SIGNALLING PATHWAYS}

\begin{tabular}{|c|c|c|c|c|c|}
\hline \multirow{6}{*}{$\frac{\text { Pathways }}{\text { Notch }}$} & Molecules & Targets & Concentrations, stages & Effects & References \\
\hline & DAPT (N-[N-(3,5- & $\gamma$-secretase inhibitor & $50 \mu \mathrm{M}$ (continuous from late gastrula) & Ectopic epidermal sensosry cells & (Lu et al., 2012) \\
\hline & $\begin{array}{l}\text { difluorophenacetyl)-I-alanyl]-S- } \\
\text { phenylglycine t-butyl ester) }\end{array}$ & & & & \\
\hline & & & $50-100 \mu \mathrm{M}$ (continuous from late blastula) & $\begin{array}{l}\text { Incomplete formation of the somites } \\
\text { segmental boundary } \\
\text { Incorrect dorso-ventral segregation of } \\
\text { somites }\end{array}$ & (Onai et al., 2015) \\
\hline & Compound $\mathrm{E}$ & $\gamma$-secretase inhibitor & not specified & Ectopic epidermal sensosry cells & (Lu et al., 2012) \\
\hline & L-685458 & $\gamma$-secretase inhibitor & not specified & Ectopic epidermal sensosry cells & (Lu et al., 2012) \\
\hline \multicolumn{6}{|c|}{ 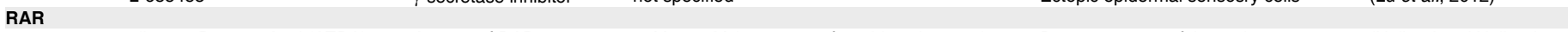 } \\
\hline & all-trans Retinoic Acid (ATRA) & Agonist of RAR & $1 \mathrm{nM}$ to $1 \mu \mathrm{M}$ (continuous from blastula stage) & Posteriorization of the embryo & $\begin{array}{l}\text { (Holland and Holland, } \\
\text { 1996) }\end{array}$ \\
\hline & & & $\begin{array}{l}1 \mu \mathrm{M} \text { (continuous from blastula stage) } \\
1 \mu \mathrm{M} \text { (continuous from blastula stage) }\end{array}$ & $\begin{array}{l}\text { Posteriorization of the embryo } \\
\text { Posteriorization of epidermal sensory } \\
\text { neurons }\end{array}$ & $\begin{array}{l}\text { (Escriva et al., 2002) } \\
\text { (Schubert et al., 2004) }\end{array}$ \\
\hline & & & $1 \mu \mathrm{M}$ (continuous from blastula stage) & Posteriorization of the pharynx & (Schubert et al., 2005) \\
\hline & & & $1 \mu \mathrm{M}$ (continuous from early gastrula stage) & $\begin{array}{l}\text { Anteroposterior patterning defects in } \\
\text { gastrula }\end{array}$ & (Koop et al., 2010) \\
\hline & & & $1 \mu \mathrm{M}$ (continuous from blastula stage) & $\begin{array}{l}\text { Hox genes expression expansion } \\
\text { anteriorly, less motor neurons. }\end{array}$ & (Schubert et al., 2006) \\
\hline & & & $\begin{array}{l}1 \mu \mathrm{M} \text { (continuous from } 6-8 \text { gill slit larvae to } 8-10 \\
\text { gill slit larvae) }\end{array}$ & Tail regression & (Koop et al., 2011) \\
\hline & & & $1 \mu \mathrm{M}$ (continuous from early gastrula stage) & Inhibition of hematopoiesis & $\begin{array}{l}\text { (Pascual-Anaya et al., } \\
\text { 2013) }\end{array}$ \\
\hline & & & $\begin{array}{l}1 \mu \mathrm{M} \text { (continuous from early-mid neurula, mid- } \\
\text { neurula and late neurula to larval stage) }\end{array}$ & $\begin{array}{l}\text { Shortening of the pharynx and loss of } \\
\text { pharyngeal structures }\end{array}$ & (Koop et al., 2014) \\
\hline & BMS009 & Antagonist of RAR & $1.5 \mu \mathrm{M}$ (continuous from blastula stage) & Anteriorization of the embryo & (Escriva et al., 2002) \\
\hline & & & $1 \mu \mathrm{M}$ (continuous from blastula stage) & $\begin{array}{l}\text { Anteriorization of epidermal sensory } \\
\text { neurons }\end{array}$ & (Schubert et al., 2004) \\
\hline & & & $1 \mu \mathrm{M}$ (continuous from blastula stage) & Anteriorization of the pharynx & (Schubert et al., 2005) \\
\hline & & & $1 \mu \mathrm{M}$ (continuous from early gastrula stage) & $\begin{array}{l}\text { Anteroposterior patterning defects in } \\
\text { gastrula }\end{array}$ & (Koop et al., 2010) \\
\hline & & & $1 \mu \mathrm{M}$ (continuous from blastula stage) & $\begin{array}{l}\text { Hox genes expression anterior limit } \\
\text { shifted posteriorly, more motor neurons }\end{array}$ & (Schubert et al., 2006) \\
\hline & & & $\begin{array}{l}2 \mu \mathrm{M} \text { (continuous from early-mid neurula, mid- } \\
\text { neurula and late neurula to larval stage) }\end{array}$ & Expansion of the pharynx & (Koop et al., 2014) \\
\hline & & & $1 \mu \mathrm{M}$ (continuous from late blastula stage) & $\begin{array}{l}\text { Enlarged pharynx and expansion of } \\
\text { pharyngeal structures }\end{array}$ & (Carvalho et al., 2017) \\
\hline & BMS493 & Antagonist of RAR & $1 \mu \mathrm{M}$ (continuous from late blastula stage) & $\begin{array}{l}\text { Enlarged pharynx and expansion of } \\
\text { pharyngeal structures, tail fin } \\
\text { elongation }\end{array}$ & (Carvalho et al., 2017) \\
\hline & R115866 & Inhibitor of Cyp26 & $500 \mathrm{nM}$ (continuous frome eraly gastrula stage) & $\begin{array}{l}\text { Shortening of the pharynx and loss of } \\
\text { pharyngeal structures }\end{array}$ & (Koop et al., 2014) \\
\hline & & & $\begin{array}{l}0,1 \text { to } 0,5 \mu \mathrm{M} \text { (continuous from late blastula } \\
\text { stage) }\end{array}$ & $\begin{array}{l}\text { Shortening of the pharynx and } \\
\text { malformation of pharyngeal structures, } \\
\text { tail fin reduction }\end{array}$ & (Carvalho et al., 2017) \\
\hline \multicolumn{6}{|c|}{ 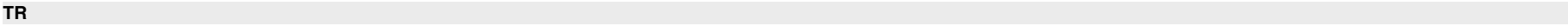 } \\
\hline & Triiodothyronine (T3) & Agonist of TR & $\begin{array}{l}\text { 10-100nM (continuous treatment from } \\
\text { premetamorphic larval stage) }\end{array}$ & Induction of metamorphosis & (Paris et al., 2008) \\
\hline & Thyroxine (T4) & Agonist of TR & $\begin{array}{l}10-100 \mathrm{nM} \text { (continuous treatment from } \\
\text { premetamorphic larval stage) }\end{array}$ & Induction of metamorphosis & (Paris et al., 2008) \\
\hline & Triiodothyroacetic acid (TRIAC) & Agonist of TR & $\begin{array}{l}\text { 10nM (continuous treatment from } \\
\text { premetamorphic larvae) }\end{array}$ & Induction of metamorphosis & (Paris et al., 2008) \\
\hline \multicolumn{6}{|c|}{ 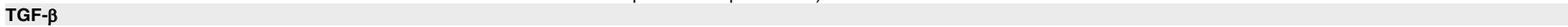 } \\
\hline & Dorsomorphin & $\begin{array}{l}\text { Inhibitor of BMP Type I } \\
\text { receptor }\end{array}$ & $8 / 16 \mu \mathrm{M}$ (continuous from late gastrula stage) & $\begin{array}{l}\text { Reduction of the number epidermal } \\
\text { sensosry cells }\end{array}$ & (Lu et al., 2012) \\
\hline & & & $20 \mu \mathrm{M}$ (continuous from early blastula stage) & Partial dorsalization of the embryo & (Kozmikova et al., 2013) \\
\hline & & & $\begin{array}{l}5 / 10 / 25 \mu \mathrm{M} \\
\text { (continuous from Knife shaped larval stage) }\end{array}$ & Mouth formation/opening affected & (Kaji et al., 2016) \\
\hline & & & $35 \mu \mathrm{M}$ (continuous from early blastula stage) & $\begin{array}{l}\text { Dorsalization of the mesendoderm } \\
\text { and absence of ectodermal cells } \\
\text { specification }\end{array}$ & (Le Petillon et al., 2017) \\
\hline & LDN-193189 & $\begin{array}{l}\text { Inhibitor of BMP Type I } \\
\text { receptor }\end{array}$ & $3 \mu \mathrm{M}$ (continuous from early blastula stage) & Partial dorsalization of the embryo & (Kozmikova et al., 2013) \\
\hline & zBMP4 & & $250 \mathrm{ng} / \mathrm{ml}$ (continuous from early blastula stage) & Ventralization of the embryo & $\begin{array}{l}\text { (Lu et al., 2012, Yu et al., } \\
2008 \text {, Yu et al., 2007) }\end{array}$ \\
\hline & & & & $\begin{array}{l}\text { Loss of neural pate border genes } \\
\text { expression }\end{array}$ & (Yu et al., 2008) \\
\hline & & & 250ng/ml (continuous from late gastrula stage) & Ectopic epidermal sensosry cells & (Lu et al., 2012) \\
\hline & mBMP2 & & $250 \mathrm{ng} / \mathrm{ml}$ (continuous from early blastula stage) & $\begin{array}{l}\text { Ventralization and posteriorization of } \\
\text { the embryo }\end{array}$ & (Kozmikova et al., 2013) \\
\hline & hActivin & & $10 \mathrm{ng} / \mathrm{ml}$ (continuous from early blastula stage) & $\begin{array}{l}\text { Dorsalization and anteriorization of the } \\
\text { embryo }\end{array}$ & (Onai et al., 2010) \\
\hline & & & $\begin{array}{l}50 \mathrm{ng} / \mathrm{ml} \text { (treatment before early gastrula stage } \\
\text { on ectodermal explants) }\end{array}$ & $\begin{array}{l}\text { The whole ectoderm expresses neural } \\
\text { markers }\end{array}$ & (Le Petillon et al., 2017) \\
\hline & mNodal & & $\begin{array}{l}8 \mu \mathrm{g} / \mathrm{ml} \\
\text { (continuous from early gastrula stage) }\end{array}$ & $\begin{array}{l}\text { Loss of asymmetrical expression Nodal } \\
\text { pathway genes }\end{array}$ & (Li et al., 2017) \\
\hline & SB505124 & $\begin{array}{l}\text { Inhibitor of } \\
\text { TGF- } \beta / \text { Nodal/Activin } \\
\text { Type I receptor }\end{array}$ & $5 / 10 \mu \mathrm{M}$ (continuous from late gastrula stage) & Loss of asymmetry & $\begin{array}{l}\text { (Bertrand et al., 2015, } \\
\text { Soukup et al., 2015) }\end{array}$ \\
\hline & & & $50 \mu \mathrm{M}$ (continuous from early gastrula stage) & $\begin{array}{l}\text { Loss of asymmetrical expression of } \\
\text { Nodal pathway genes }\end{array}$ & (Li et al., 2017) \\
\hline & & & $\begin{array}{l}5 \mu \mathrm{M} \text { (from prehatching neurula to hatching } \\
\text { neurula stage) }\end{array}$ & Loss of orobranchial structures & (Kaji et al., 2016) \\
\hline
\end{tabular}


TABLE 2 (CONTINUED)

\section{SUMMARY OF PHENOTYPES OBTAINED AFTER PHARMACOLOGICAL TREATMENTS INTERFERING WITH DIFFERENT SIGNALLING PATHWAYS}

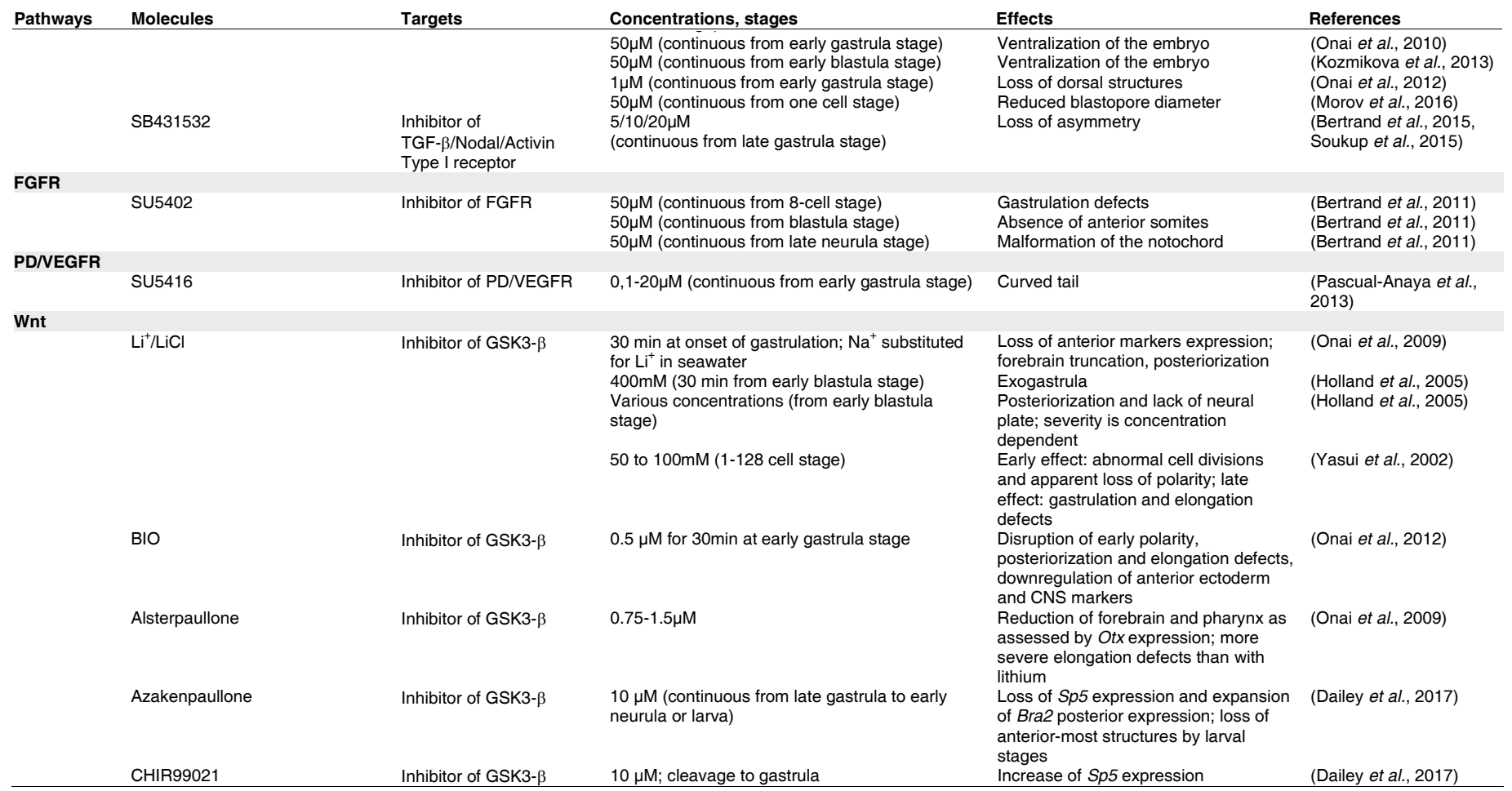

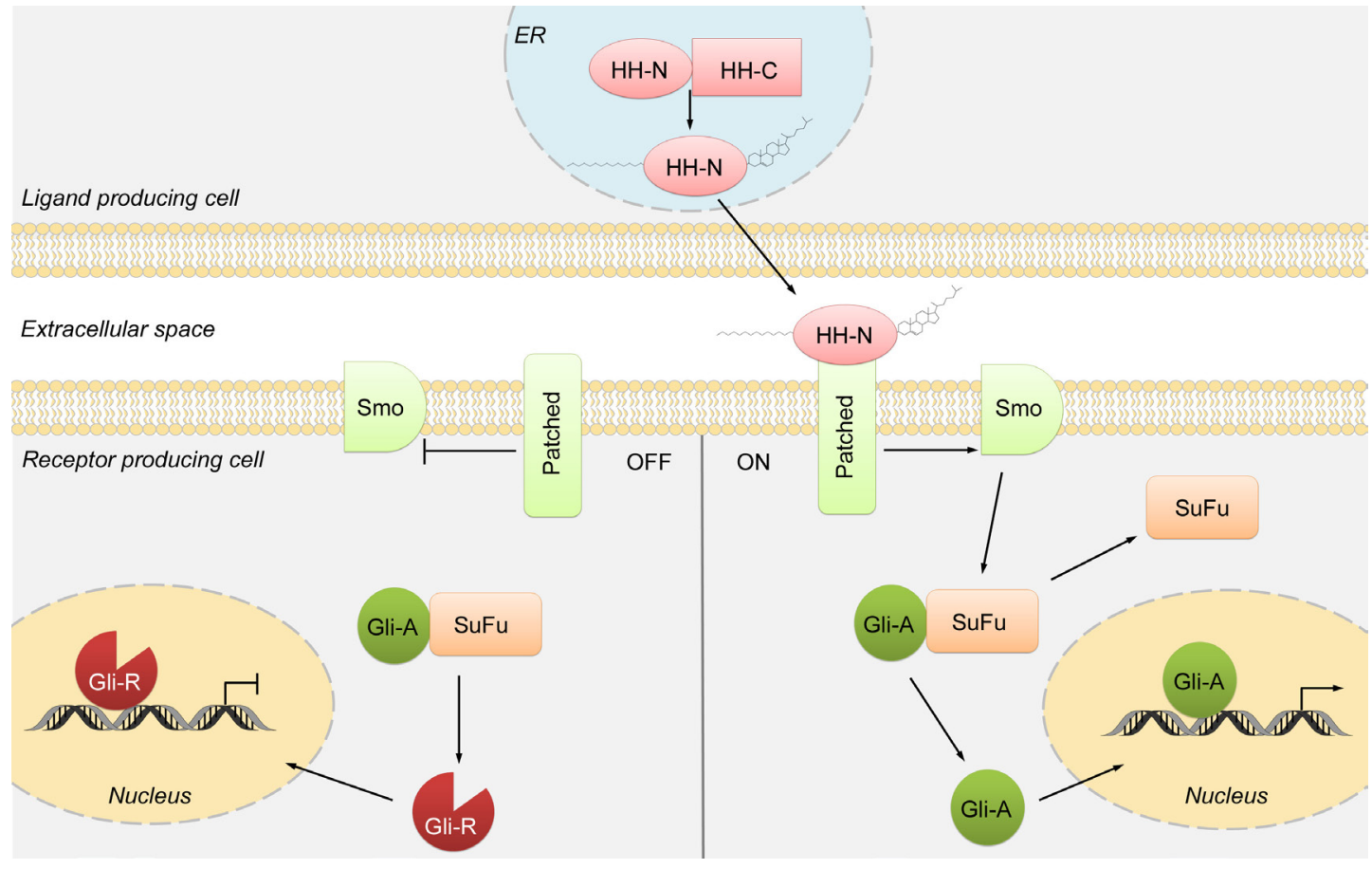

Fig. 3. Simplified schematic view of the canonical hedgehog (Hh) signalling pathway. In the ligand producing cell, Hh undergoes autoproteolytic cleavage releasing the $\mathrm{N}$-terminal domain (HH-N) from the C-terminal domain (HH-C). $\mathrm{HH}-\mathrm{N}$ is subsequently linked to a palmitate in its $\mathrm{N}$-terminus and to a cholesterol molecule in its $C$-terminus, probably in the endoplasmic reticulum (ER). In the absence of Hh (OFF), the transmembrane receptor Patched inhibits the orphan GPCR Smoothened (Smo), leading to the proteolysis of the transcription factor Gli, sequestered by Sufu (Suppressor of Fused homolog), which is converted into its repressorform (Gli-R). Gli-R acts by repressing the transcription of Hh pathway target genes in the nucleus. When Hh binds to Patched (ON), Smoothened inhibition is released leading to the dissociation of Gli from Sufu. Gli is therefore in its active form (Gli-A) and enters the nucleus to activate the transcription of Hh pathway target genes. 
At the late neurula stage, a new expression domain is observed in the anterior pharyngeal endoderm (Holland et al., 2001). At later stages, Notch is expressed in the tailbud, the cerebral vesicle and Hatcheck's left diverticulum (Holland et al., 2001). The expression of Notch has also been analyzed in B. lanceolatum, where it was shown to be quite similar to that in the Florida species. However, expression in the pharyngeal endoderm and cerebral vesicle can also be detected at an earlier developmental stage (mid-neurula) in the European species (Somorjai et al., 2008).

In vertebrates at least 5 ligands are known: Jagged 1 and 2 and Delta-like 1, 3, and 4 (Wang, 2011). Although two genes for ligands of the Jagged family have been found in the $B$. floridae genome (Gazave et al., 2009), only cloning and expression of the single Delta gene, orthologous to vertebrate Delta-like genes (Gazave et al., 2009), was reported (Rasmussen et al., 2007). The Delta protein of amphioxus contains a signal peptide, a DSL domain and nine EGF repeats (Rasmussen et al., 2007). Delta expression, as for Notch, is first observed at the gastrula stage, in the dorsal mesendoderm region (Rasmussen et al., 2007). Then, expression becomes restricted to the paraxial mesoderm and is observed after hatching in the two first pairs of somites before they begin to form, and in some cells of the neural plate (Rasmussen et al., 2007). As development proceeds, transcripts are also detected in some epidermal cells in the ventral region (Rasmussen et al., 2007). At the late neurula stage, Delta is expressed in the posterior part of somites, in some neural plate cells, in ectodermal cells on both sides of the embryo, and in the pharyngeal endoderm (Rasmussen et al., 2007). In the larva, expression is mainly observed in the forming somites budding from the tailbud, in some cells of the club-shaped gland and in the most anterior pharyngeal cells (Rasmussen et al., 2007).

It is interesting to note that the expression patterns of Notch and Delta are not fully overlapping. Concerning the expression of Notchin territories in which Delta is not expressed, we might expect another ligand coding gene (from the Jagged family possibly) to be transcribed, although we cannot exclude Notch activation through a non-canonical pathway (Andersen et al., 2012) in such regions.

\section{Other actors}

The only other actor of the Notch pathway for which expression data are available is Fringe (Mazet and Shimeld, 2003), the ohnolog of lunatic fringe, radical fringeand manic fringe in vertebrates. Fringe proteins are glucosaminyltransferases that have been shown to modulate Notch activity by initiating elongation of O-linked fucose residues attached to the EGF repeats of its ectodomain (Bruckner et al., 2000, Moloney et al., 2000). In a first study, amphioxus Fringe expression was detected at the late gastrula stage in the anterior neural plate (Mazet and Shimeld, 2003). Then, neural expression becomes segmented as somites start to form, and Fringe transcripts are detected in the posterior endoderm and in the endodermal cells that are fated to become the dorsal midline of the embryonic gut (Mazet and Shimeld, 2003). In late neurula stage embryos, Fringe is expressed in the cerebral vesicle and in the anterior and posterior endoderm (Mazet and Shimeld, 2003). In a more recent study, Fringe expression was detected earlier during gastrulation, in the ventral mesendoderm, with a dorsal boundary just adjacent to the Delta expressing paraxial mesoderm territory (Onai et al., 2015).

\section{Functional studies}

Notch pathway function has mainly been studied using treatments with DAPT(N-[N-(3,5-difluorophenacetyl)-I-alanyl]-S-phenylglycine t-butyl ester), a $\gamma$-secretase inhibitor (Dovey et al., 2001) that inhibits Notch receptor cleavage, thereby impeding Notch pathway activation by any ligand. Amphioxus possesses a dorsal central nervous system and a peripheral nervous system composed of several populations of epidermal sensory neurons (ESNs) (Wicht and Lacalli, 2005). Among these cells, the type I solitary neurons are the most abundant, and their progenitors express Delta, together with the neural bHLH factor achaete-scute homologue at the neurula stage (Lu et al., 2012). Lu and colleagues showed that inhibiting the Notch pathway using DAPT, and other $\gamma$-secretase inhibitors, induces the formation of more ESN progenitors, which are then grouped in clusters containing more cells than in control embryos (Lu et al., 2012). This experiment suggests that Delta/
Fig. 4. Simplified schematic view of the canonical Notch signalling pathway. When a Notch family receptor interacts with its transmembrane ligand produced by a neighbouring cell, the extracellular domain is first cleaved by extracellular metalloproteases. The Notch intracellular domain (NICD) is then released after intracellular cleavage bya $\gamma$-secretase complex. NICD then enters the nucleus where it interacts with a DNA binding protein, CSL (CBF1/RBPjк/Su(H)/Lag-1). Together they recruit a co-activator called Mastermind (MAM) to activate the transcription of target genes.

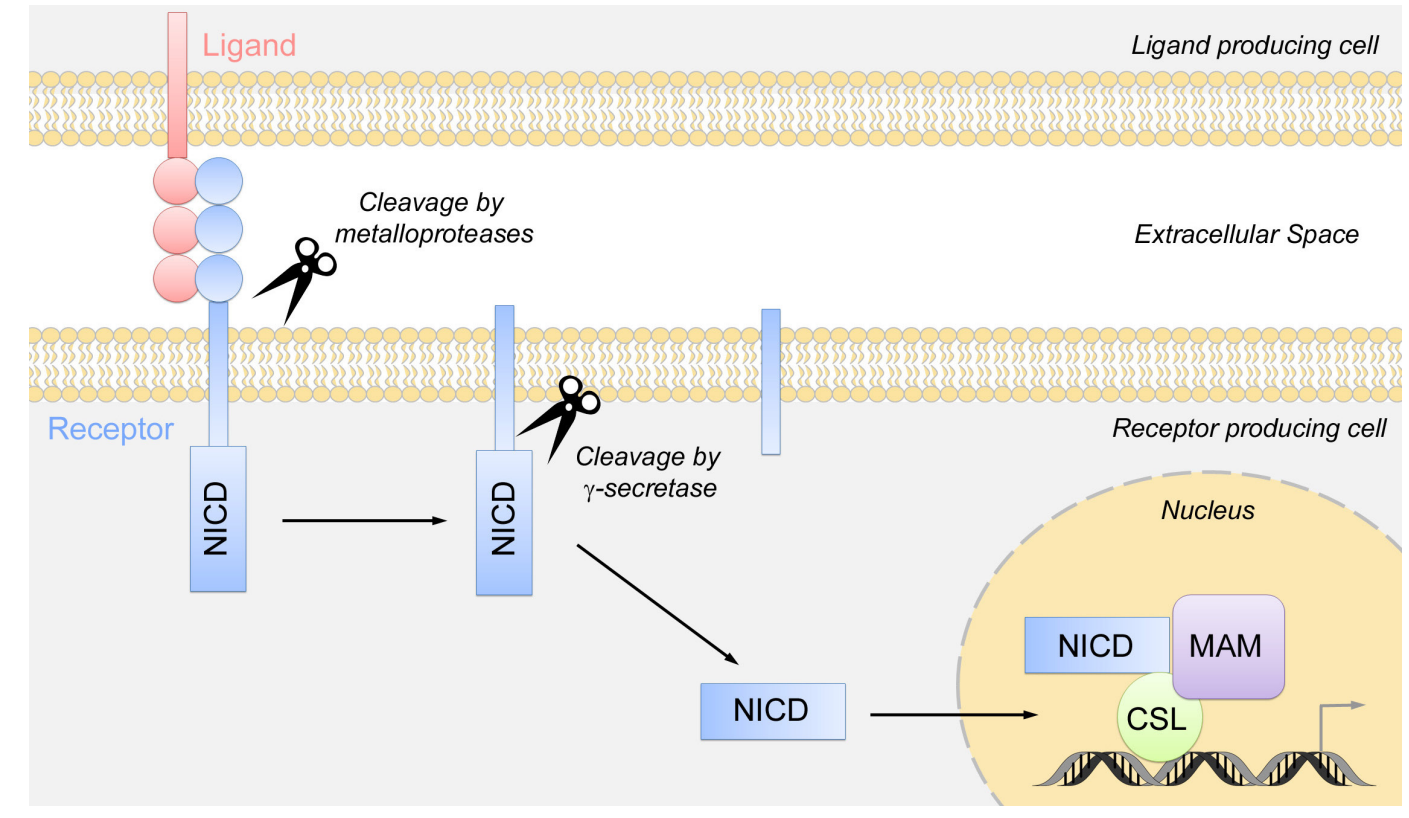


Notch-mediated lateral inhibition would be required in amphioxus for the specification of individual sensory neurons, as is the case in other animals like Drosophila (Lu et al., 2012). In vertebrates, the Delta/Notch pathway is implicated in the segmentation of the paraxial mesoderm, which forms somites. Onai and colleagues studied the role of Notch signalling during somitogenesis in amphioxus (Onai et al., 2015). They showed that after DAPT treatments, the enterocoelic somites, which normally form from the paraxial dorsal mesendoderm, are not completely separated from the archenteron roof, and that the boundaries between somites are not apparent (Onai et al., 2015). The authors suggest that in amphioxus, the Notch signal would be important for the correct dorso-ventral segregation of somites as well as for antero-posterior boundary formation between somites (Onai et al., 2015).

\section{Nuclear receptors}

\section{How do they work?}

Nuclear receptors (NRs) are ligand-activated transcription factors that consist of a modular structure comprising two major functional domains. These include the $\mathrm{N}$-terminal domain (i.e. DNA binding domain, DBD), which is responsible for the interaction between the NRs and the response elements present in the promoter region of their target genes, and the C-terminal domain (i.e. ligand binding domain, LBD), which interacts with the ligands and with co-regulators to control gene expression (Gronemeyer etal., 2004). Thus, NRs occupy a special position in gene regulation since they provide a direct link between the ligand, which they bind, and the target genes, whose expression they regulate. However, not all NRs have a ligand and some of them, the so-called orphan receptors, either function through the binding of an unknown ligand, or control expression of their target genes without binding any ligand (Benoit et al., 2006). Known ligands in vertebrates include many different lipophilic molecules of different chemical natures, such as steroids, thyroid hormones, retinoic acid, or even fatty acids (Robinson-Rechavi et al., 2003). Mammalian genomes contain 48-49 different NRs, grouped into 7 subfamilies (NR0-NR6) including 19-20 paralogy groups (Escriva Garcia et al., 2003). The $B$. floridae genome contains $33 \mathrm{NRs}$, including members of all the mammalian paralogy groups except two (NR1//J/K and NR2F) (Schubert et al., 2008). However, a NR2F gene has been cloned and studied (COUP-TF), indicating that genome data are incomplete (Langlois et al., 2000). Moreover, amphioxus also has a member of the NR5B subfamily, which is not present in vertebrates and was only known in ecdysozoans; and a member of a completely new subfamily, NR7, which is not present in vertebrates but that has been found in echinoderms. Furthermore, amphioxus shows some lineage specific duplications for the NR1H and the NR2E subfamilies. Analyses of gene expression and functional studies have only been undertaken for a few of the amphioxus NRs. We will detail below expression and functional data for these receptors.

\section{Expression patterns of nuclear receptors}

Gene expression has been studied for only a few NRs in amphioxus, including NR1 A (Paris et al., 2008a) and NR1B (Escriva et al., 2002) (thyroid hormone receptor - TR, and retinoic acid receptor - RAR, respectively), NR2B (RXR) (Escriva et al., 2002), NR2C (TR2/4) (Escriva et al., 2002), NR2F (COUP-TF) (Langlois et al., 2000), NR3A, B and C (ER, ERR and SR, respectively) (Bardet et al., 2005, Bridgham et al., 2008) and NR4A (Nurr1/NGFIB/NOR1) (Candiani et al., 2009).

The biological functions of retinoic acid (RA) are mediated by heterodimers of two NRs: RAR and RXR. RXR also acts as an heterodimer of other nuclear receptors in accordance with its broad and weak expression throughout all developmental stages in amphioxus (Escriva et al., 2002). In contrast, by the mid-gastrula stage, $R A R$ is expressed throughout the mesendoderm and more weakly throughout the ectoderm. At the early neurula stage expression becomes downregulated anteriorly in the different tissues where it is expressed (i.e. the neural plate, the anterior endoderm and the non-neural ectoderm), but remains high in the posterior mesoderm, somites and in the posterior three-quarters of the neural plate and endoderm (Escriva et al., 2002). Later on, at the mid-neurula stage, expression is also downregulated in the posterior third of the endoderm, and the only remaining strong expression is in the nerve cord, posterior to the cerebral vesicle, in the somites of the middle third of the embryo and in a small region of the endoderm. In late neurulae, $R A R$ expression is limited to the nerve cord posterior to the cerebral vesicle and to the endoderm at low levels. Finally, in larvae, $R A R$ is expressed only in the middle third of the nerve cord, somites and gut (Escriva et al., 2002).

$T R 2 / 4$ shows an expression pattern complementary to $R A R$ (Escriva et al., 2002). Thus, expression is first detected at the early neurula stage in the anterior neuroectoderm, particularly in the future cerebral vesicle, and in the dorso-anterior endoderm. Later on, at the mid-neurula stage, expression is most intense posteriorly and anteriorly, especially in the posterior mesoderm, cerebral vesicle and Hatcheck's left diverticulum, which is homologous to part of the vertebrate pituitary. In late neurulae, expression is strong in the cerebral vesicle, in Hatschek's left diverticulum and in the primordia of the mouth and first gill slit. There is also weak expression in the gut. At the late neurula stage, before the mouth opens, expression persists in the tailbud, cerebral vesicle and in pharyngeal structures (in the forming mouth, first gill slit and Hatschek's left diverticulum). This expression remains until the larval stage except in the tailbud (Escriva et al., 2002).

Gene expression of the amphioxus thyroid hormone receptor (TR) has only been studied quantitatively using RT-qPCR. The authors showed that TRexpression is low during embryonic development, increases in pre-metamorphic larvae just before metamorphosis, and then decreases in juveniles and adults (Paris et al., 2008a).

The amphioxus orthologue of COUP-TF NRs is not expressed during early development and transcripts only start to be detected by in situ hybridization at the late larval stage (4-5 gill slit larvae) in the neural tube posterior to the cerebral vesicle, the homologue of the vertebrate hindbrain and spinal cord, and in dorsal and lateral groups of cells which form dorso-ventral stripes in the nerve cord (Langlois et al., 2000).

The estrogen related receptor gene (ERR) shows an interesting expression pattern during amphioxus embryonic development (Bardet et al., 2005). Transcripts are first detected at the neurula stage in the dorsal part of somites 2 to 6 , and then in the newly formed somites when the neurula elongates. From the mid-neurula stage, ERR starts to be expressed in individual mesodermal and epidermal cells, but this expression disappears in later stages when $E R R$ starts to be weakly expressed in the pharyngeal endoderm. Other expression sites at mid-neurula stage are the frontal eye, the presumptive photoreceptor of Hesse and other neuronal derivatives. 
$E R R$ is expressed from this developmental stage in paired cells in the neural tube, from the border between somites 1 and 2 up to somite 4 , and this pattern is extended in later stages until labelling is observed in six pairs of cells. This segmented pattern remains until the larval stage when a new expression domain appears in the posterior part of the cerebral vesicle (Bardet et al., 2005).

Expression studies for other NRs of subfamily 3 have also been published, but only in adults. Thus, while estrogen receptor $(E R)$ and steroid receptor $(S R)$ genes are co-expressed in the cytoplasm of the oocytes in the female gonads, only $E R$ is expressed weakly in the gills. In males, $S R$ is expressed broadly throughout the testes, at all stages of spermatogenesis, and ER is expressed in the germinal epithelium of the testis in a narrow band of cells that are likely to be early spermatogonia (Bridgham et al., 2008).

The last NR for which gene expression has been documented is the orthologue of Nurr1/NGFIB/NOR1, which shows a restricted expression pattern in late neurula stage embryos in the ventromedial wall of the Hatschek's left diverticulum and in the posterior region of the pre-oral pit of larvae (Candiani et al., 2009).

\section{Other actors}

Nuclear receptor-mediated transactivation of target genes implies direct contact between the receptor and co-regulators (coactivators or co-repressors). Although orthologues of vertebrate co-regulators are present in the B. floridaegenome (Schubert et al., 2008), no expression or functional data have been published. However, several studies have shown that mammalian co-regulators are able to interact with several amphioxus NRs. Thus, amphioxus TR in the presence of its ligand TRIAC (3,5,3'-triiodothyroacetic acid) interacts with the co-activator SRC-1 (Steroid Receptor Coactivator 1) (Paris et al., 2008a), amphioxus RXR interacts with the co-activator hTIF2 (human Transcriptional Intermediary Factor 2 ) in the presence of its ligand 9-cis RA (Tocchini-Valentini et al., 2009) and amphioxus ERRs (there are two isoforms of this receptor in amphioxus, long and short ERR), interact with the mammalian SRC-1, GRIP1 (Glutamate Receptor Interacting Protein 1), TIF1 (Transcriptional Intermediary Factor 1) and RIP140 (ReceptorInteracting Protein 140) (Horard et al., 2004).

Other actors playing important roles in NR signalling pathways are enzymes implicated in ligand anabolism and catabolism. However, while the presence of many genes for these enzymes has been described in amphioxus (e.g. enzymes implicated in steroid metabolism such as cytochrome P450 (CYP11A, CYP17, and CYP19) and the 17 $\beta$-hydroxysteroid dehydrogenase) (Castro et al., 2005, Mizuta and Kubokawa, 2007), gene expression and/ or function has only been characterized for enzymes involved in the synthesis and degradation of RA, and for CYP19 aromatase. Using semi-quantitative RT-PCR, it was shown that the CYP19 is expressed in the middle third of amphioxus adults and preferentially in females (Callard et al., 2011, Castro et al., 2005). Otherenzymes for which the expression pattern has been characterized include the retinoic acid degradation enzyme CYP26. Three CYP26 genes (CYP26 1-3), which originated by tandem duplication, are found in amphioxus (Carvalho et al., 2017). The expression profiles of CYP26-1 and CYP26-3 are quite similar and weak, starting at the mid-gastrula stage in the lateral anterior mesoderm. Then, in mid-neurulae, expression is detected in the anterior somites and in the anterior central nervous system. A slight difference is then found in the larvae where CYP26-1 is more strongly expressed in central and posterior regions, whereas CYP26-3 labelling is more intense in central and anterior regions. The expression of CYP26-2 starts at the mid-gastrula stage around the blastopore and, later, an expression domain appears in the presumptive lateral mesoderm and anterior neuroectoderm. At the mid-neurula stage, expression is detected in the anterior somites and neuroectoderm, but also in the most anterior and posterior tips of the ectoderm and endoderm and in the tailbud. In late neurulae, before the mouth opens, it is expressed in all anterior germ layers and at the posterior end in the ectoderm. Finally, in larvae, the overall domains of CYP26-2 expression are maintained, with conspicuous labelling anteriorly and posteriorly and a weaker signal in the centre (Carvalho et al., 2017). RA producing enzyme (aldehyde dehydrogenases, ALDHs) expression patterns have also been studied in amphioxus (Sobreira et al., 2011), which possesses 6 ALDH1 genes and one ALDH2 (Canestro et al., 2006). Amphioxus ALDH1a is expressed caudally close to the developing tailbud with a sharp anterior boundary at the mid-neurula stage (Sobreira et al., 2011). Later, it is detectable in the posterior gut endoderm of late neurulae. The expression of $A L D H 1 d$ overlaps with that of $A L D H 1 a$ at the mid-neurula stage, but in late neurulae, expression is broad and slightly stronger in the posterior gut (Sobreira et al., 2011). Other ALDH1 genes, such as $A L D H 1 b, A L D H 1 c, A L D H 1 e$, and $A L D H 1 f$ are weakly expressed in posterior domains overlapping with that of ALDH1a in mid-neurula stage embryos (Sobreira et al., 2011). However, by the late neurula, they are expressed diffusely and weakly throughout the amphioxus embryo with a weak to moderate concentration of the signal for ALDH1b, ALDH1c, and ALDH1e in the posterior gut (Sobreira et al., 2011). ALDH2 expression is restricted to posterior mesendodermal tissues at the mid-neurula stage and, subsequently, spreads throughout the embryo in late neurulae (Sobreira et al., 2011).

\section{Functional studies}

Pharmacological treatments with molecules that are agonist or antagonist ligands of NRs have been used to study the function of NRs during embryonic development in amphioxus. In this context, the most studied function has been the role of RA during embryonic development using all-trans RA itself as well as RA antagonists (BMS009, BMS493). An excess of RA induces a posteriorization of the embryo, whereas the use of antagonists of RAR induces anteriorization (Escriva et al., 2002). This role of RA in anteroposterior patterning starts at the early gastrula stage (Koop et al., 2010) and affects different tissues, such as the ectoderm, through the control of antero-posterior patterning of epidermal sensory neurons (Schubert et al., 2004); or the endoderm, where RA establishes the posterior limit of the pharynx through control of Hox1 expression (Schubert et al., 2005). Besides this role in patterning, RA also controls pharynx segmentation (Koop et al., 2014), neuronal specification (Schubert et al., 2006), or even tissue remodelling in the amphioxus tail (Koop et al., 2011) and tail fin formation (Carvalho et al., 2017). Finally, treatment of neurula stage embryos with RA was shown to inhibit hematopoiesis in amphioxus (Pascual-Anaya et al., 2013).

Another receptor for which the developmental function has been studied is TR. It has been shown that amphioxus metamorphosis is controlled by a thyroid hormone, the 3,5,3'-triiodothyroacetic acid (TRIAC), through its binding to TR and its activation (Paris et al., 2008a). 
Other functional studies on amphioxus NRs concern their molecular capacities to bind DNA and to homo- or heterodimerize. Using in vitro EMSA (Electro Mobility Shift Assay) approaches, TR has been shown to bind both as homo- or heterodimer with RXR to DR4 (Direct repeat 4) and HREpal (Hormone Response Element palindrome) elements (Paris et al., 2008a). RAR heterodimerizes with RXR and binds classical DR5 response elements, as well as an IR7 (Inverted Repeat 7) element found in the 5' non coding region of $T R 2 / 4$. This receptor, $T R 2 / 4$, also binds to this IR7 and to DR5 elements (Escriva et al., 2002). In addition, RXR binds as a heterodimer with TR and RAR to DR4 and DR5 elements, respectively, and as a homodimer to DR1 elements (Escriva et al., 2002). COUP-TF can bind elements ranging from DR0 to DR5 with different affinities (Langlois et al., 2000). Finally, receptors of the NR3 subfamily (i.e.; ERR, ER, SR) bind ERE (Estrogen Response Element). Thus, ERR, which is expressed as two isoforms (a short and a long isoform), binds ERE as homo- or heterodimers formed by the two isoforms, or to SFRE (Steroidogenic Factor Binding Element) as a homodimer for the short isoform, and as monomer for the long isoform (Horard et al., 2004). ER and SR also bind to ERE as homodimers (Bridgham et al., 2008, Paris et al., 2008a). These results show that, globally, amphioxus NRs function in a similar way as their vertebrate orthologues, except for SR, which can bind ERE, in contrast to its vertebrate orthologues AR (Androgen Receptor), MR (Mineralocorticoid Receptor), PR (Progesterone Receptor) and GR (Glucocorticoid Receptor) (Bridgham et al., 2008).

The ligand binding capacity of different NRs has also been tested either directly (using limited proteolysis assays or mass spectrometry) or indirectly (using a transactivation assay after transient transfection). Thus, RAR binds all-trans and 9-cis RA (Escriva et al., 2006), similarly to its vertebrate orthologues with similar affinities, but TR does not bind vertebrate thyroid hormones (triiodothyronine (T3) or thyroxine (T4)). However, a new ligand was discovered in amphioxus which is a thyroid hormone derivative, TRIAC, that binds with high affinity to the amphioxus TR (Paris et al., 2008a). Other receptors for which ligand binding has been studied are RXR, which binds several molecules such as 9-cis RA, DHA (DocosaHexaenoic Acid) or oleic acid (with lower affinities than vertebrate RXRs) (Tocchini-Valentini et al., 2009). TR2/4 does not bind any ligand but is able to transactivate expression of a reporter gene controlled by an IR7 element and also to inhibit the transactivation of the RAR-RXR heterodimer by competing for the DR5 response element (Escriva et al., 2002).

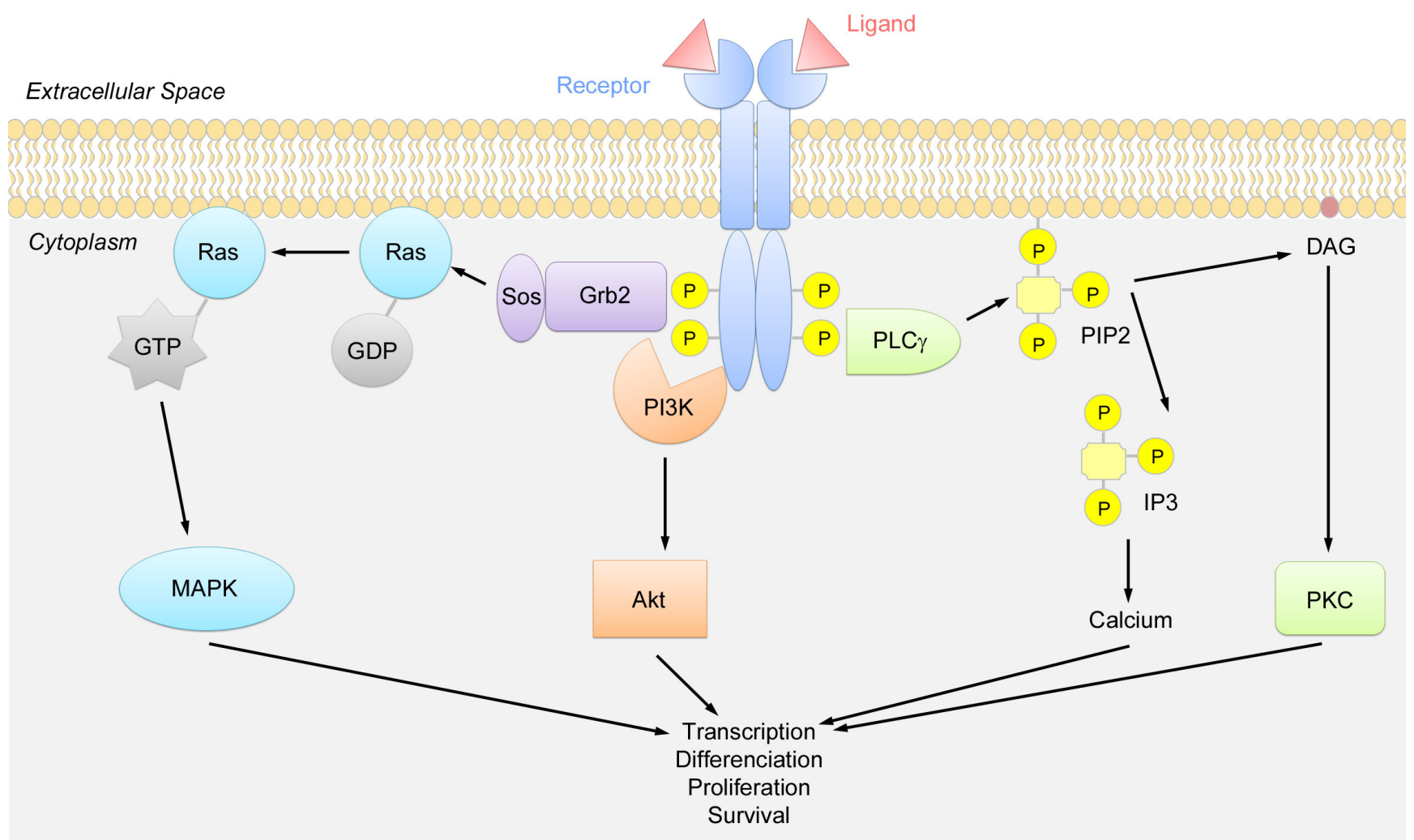

Fig. 5. Simplified schematic view of the receptor tyrosine kinase (RTK) canonical signalling pathway. RTK are transmembrane receptors and interaction of dimers with their ligands induces a transphosphorylation on tyrosine residues of the intracellular domain. The phosphorylated cytoplasmic domain interacts with the adaptor protein Grb2 (Growth factor receptor-bound protein 2), which is associated with the Ras-guanine exchange factor Sos (Son of sevenless) that transforms Ras-GDP into Ras-GTP. This is the first step of activation of the MAPK (Mitogen-activated protein kinase) cascade, which ends with the activation of target gene transcription. Phosphorylated receptors also interact with PI3K (phosphatidylinositide 3-kinase) and PLC $\gamma$. Active PI3K then activates Akt whereas PLC $($ Phospholipase $C$ - $\gamma$ ) catalyzes the formation of two secondary messengers, inositol 1,4,5-trisphosphate (IP3) and diacylglycerol (DAG), from phosphatidylinositol 4,5-bisphosphate (PIP2). IP3 diffuses in the cytoplasm and, through interaction with its receptor, induces the release of $\mathrm{Ca}^{2+}$ from the endoplasmic reticulum resulting in an increase of $\mathrm{Ca}^{2+}$ cytoplasmic concentration. DAG activates PKC (Protein Kinase (), which phosphorylates several substrates. The integration of the activation of the three intracellular cascades leads to many different outputs at the cellular level. 
COUP-TF is also able to inhibit receptor-mediated activation of transcription of different mouse receptors bound to different response elements from DR1 to DR5 and ERE (Langlois et al., 2000). The orphan receptor ERR can also transactivate through an ERE (both long and short isoforms); however, on an SFRE, only the short isoform can transactivate, while the long isoform has no effect (Horard et al., 2004). The other steroid receptors, ER and SR, do not behave as classical vertebrate steroid receptors in amphioxus. Thus, amphioxus ER does not bind estrogens and it has only been shown to bind BPA (bisphenol A). In contrast, SR binds estrogens with low affinity (Bridgham et al., 2008, Paris et al., 2008b). Thus, amphioxus ER behaves as a dominant negative estrogen receptor in mammalian cells, even in the presence of BPA (Paris et al., 2008b), while SR transactivates in the presence of estrogens (Bridgham et al., 2008). Finally, the last group of receptors for which ligand-binding capacities have been studied is the $\mathrm{NR} 1 \mathrm{H}$ subfamily (LXR and FXR). Amphioxus possesses 10 paralogues of the FXR/LXR (Farnesoid X Receptor/Liver X Receptor) subfamily due to a lineage-specific duplication event (Lecroisey et al., 2012, Schubert et al., 2008), with one of them being a clear orthologue of vertebrate LXR. Phylogenetic approaches only clarified the orthology of 5 of the other receptors with vertebrate FXRs (Fonseca et al., 2017). Ligand binding has been characterized using transient transactivation assays for the amphioxus LXR with four different ligands (the synthetic molecule T0901317, and the natural ligands 24(S)-hydroxycholesterol, 25-hydroxycholesterol and 24(S),25epoxycholesterol). While the amphioxus LXR is able to bind and transactivate a reporter gene in the presence of these ligands, it shows a low binding affinity for them compared with its vertebrate orthologues (Fonseca et al., 2017).

\section{Receptor tyrosine kinase pathway}

\section{How does it work?}

Receptor Tyrosine Kinases (RTKs) consist of a superfamily of transmembrane proteins presenting a variety of extracellular domain combinations and a tyrosine kinase cytoplasmic domain. The RTKs are receptors for several growth factors, as well as for some cytokines and hormones. The interaction between the receptors and their ligands usually induces a stabilization of a dimer of receptors that can transphosphorylate each other on tyrosine residues present in the intracellular domain (Lemmon and Schlessinger, 2010) (Fig. 5). This phosphorylation then allows interaction with several proteins that in turn are able to activate different cytoplasmic signalling cascades such as the MAPK (mitogen activated protein kinase) pathway, the PLC $\gamma$ (Phospholipase C- $\gamma$ ) pathway or the PI3K (phosphatidylinositide 3-kinase) pathway (Fig. 5).

The analysis of RTK gene content in amphioxus showed that it possesses at least one member of each of the subfamilies that are widespread in bilaterians (19 families) (D'Aniello et al., 2008). Amphioxus has generally one member of each of these subfamilies, but also some lineage-specific duplications, giving rise to 22 genes coding for proteins of the NOK family, 8 genes that are related to MET and AXL families, and 47 genes coding for receptors related to TIE, PD/VEGFR, RET, and FGFR families, which were named EXTKs (D'Aniello et al., 2008). However, analyses of gene expression have only been undertaken for a few of the receptors or their ligands. We will detail below expression and functional data for these specific RTKs.

\section{Erythropoietin-producing human hepatocellular receptors}

The EPH (erythropoietin-producing human hepatocellular receptors) gene family can be separated into two groups in vertebrates: the EPHAgroup, which contains up to 10 members; and the EPHB group, with 6 members. In amphioxus, two genes, EPH1 and $\mathrm{EPH} 2$, resulting from a specific duplication in the cephalochordate lineage, were discovered in the $B$. floridae genome (D'Aniello et al., 2008, Mellott and Burke, 2008). They are both ohnologous to all the EPH genes from vertebrates, and they code for receptors with an EPH ligand binding domain, a TNFR (Tumor Necrosis Factor Receptor) domain, and two fibronectin III domains in the extracellular region (D'Aniello et al., 2008). In B. lanceolatum, $E P H 1$ is expressed in the blastopore of gastrula stage embryos (Bosne, 2010). During neurulation, expression is detected in the cerebral vesicle and in the paraxial mesoderm. At the late neurula stage, before the mouth opens, EPH1 transcripts are detected in the anterior and posterior notochord, in the somites, the neural tube and in the pharyngeal endoderm. In the larva, expression is observed in the anterior and posterior notochord, in the cerebral vesicle as well as in the mouth, the club-shaped gland, the endostyle and the pre-oral pit. The other receptor gene, EPH2, shows ubiquitous expression until the late neurula stage (Bosne, 2010). Prior to mouth opening, expression is stronger in the pharyngeal endoderm and in anterior and posterior notochord. In the larva, $E P H 2$ transcripts are detected in the mouth and in the pharynx.

Ephrins (Eph receptor-interacting proteins), the ligands for $\mathrm{EPHs}$, are membrane-bound proteins, implying that activation of the EPH signalling pathway is only possible through direct cellcell interaction. Two families of ligands are known in vertebrates, the EfnA and the EfnB groups. In amphioxus, there are three Efn genes (Efn1, 2 and 3 ) that result from a lineage-specific duplication in cephalochordates (Bosne, 2010). It is, up to now, not clear whether they are more closely related to EfnA or EfnB groups from vertebrates, although it has been proposed that group A may only be present in Olfactores (the clade containing vertebrates and urochordates) (Mellott and Burke, 2008). The expression patterns of Efn1 and Efn2 have been described in B. lanceolatum (Bosne, 2010). Efn 1 is expressed in the mesendoderm of the blastopore region of gastrulating embryos. At the neurula stage, expression is observed in the paraxial mesoderm and in some neurons in a segmented manner. At the late neurula stage, before mouth opening, Efn1 transcripts are detected in the pharynx, in the posterior presumptive gut and in the tailbud. In the larva, expression is restricted to the mouth, the pharynx and the cerebral vesicle. At the gastrula stage Efn2 is ubiquitously expressed, and in neurulae expression is widespread in the mesendoderm, although not in the most posterior region. Before the mouth opens, Efn2 transcripts are observed in the ventral pharyngeal endoderm, in the presumptive endostyle region and in the posterior part of the future gut. In larvae, Efn2 is expressed mainly in the pharynx. No functional data on the role of the EPH signalling pathway during amphioxus embryogenesis have been described so far.

\section{Fibroblast growth factor receptor}

Amphioxus has a unique FGFR (Fibroblast Growth Factor Receptor) gene, coding for a receptor with three Immunoglobulin extracellular domains, similarly to the four receptors found in vertebrates (D'Aniello et al., 2008, Suga et al., 1999). During embryogenesis, FGFR is first expressed at the gastrula stage in 
the anterior mesendoderm (Bertrand et al., 2011). During neurulation, expression is detected in the presomitic mesoderm and later on in presumptive notochord and somitic regions. At the late neurula stage, before the mouth opens, FGFR is expressed in the notochord, the anterior endoderm and the somites forming from the tailbud. In the larva, labelling is detected in the anterior pharyngeal endoderm, in the notochord, and at a lower level in the gut, except in the ilio-colonic region (Bertrand et al., 2011).

FGFs are small proteins that are usually secreted. Eight FGF genes have been found in the $B$. floridae genome, but the orthology relationships with vertebrate FGFs are well supported using phylogenetic reconstruction for only three of them, namely $F G F 1 / 2$, FGF8/17/18 and FGF9/16/20 (Bertrand et al., 2011). However, synteny conservation analyses suggests that $F G F A$ belongs to the FGF3/7/10/22 paralogy group, FGFB to the $F G F 4 / 5 / 6$ group and FGFC to the FGF19/21/23group. In contrast, no orthology relationships with vertebrate FGFs could be proposed for FGFD and FGFE. Here we will keep this nomenclature of amphioxus FGFs even if other studies suggested different orthology relationships for some of the 8 amphioxus FGFs (Oulion et al., 2012). The expression of these ligands is very diverse and dynamic (Bertrand et al., 2011). FGF1/2 is ubiquitously expressed during embryogenesis, whereas FGFB and FGFD expression could not be detected using in situ hybridization. FGF8/17/18 and FGF9/16/20 are the first FGFs to show a regionalized expression at the gastrula stage. They are expressed complementarily in the dorsal part of the gastrula with FGF9/16/20 labelling being observed in the presumptive neural plate and $F G F 8 / 17 / 18$ being expressed in the dorsal mesendoderm. At the neurula stage, expression of $F G F 8 / 17 / 18$ completely fades in the mesendoderm and appears in the future cerebral vesicle, whereas FGF9/16/20 is expressed in the neural tube and in the pharyngeal endoderm. At this stage FGFA expression starts in the cerebral vesicle and in the pharyngeal endoderm as well as in the mesoderm with an antero-posterior gradient. Later on, FGF8/17/18 expression disappears in the cerebral vesicle and is observed in the most anterior tip of the epidermis, and in two regions of the pharyngeal endoderm corresponding to the future mouth and first gill slit territories in B. lanceolatum and B. floridae (Bertrand et al., 2011, Meulemans and Bronner-Fraser, 2007). This pattern is observed until the larva stage. At the late neurula stage FGF9/16/20 is expressed in a broad region of the ventral pharyngeal endoderm as well as in the neural tube and, in the larva, labelling is detected in the club-shaped gland, the first gill slit, the midgut as well as in the anus. FGFA is expressed in the cerebral vesicle and anterior ventral pharyngeal endoderm during late neurula stages, and in the endostyle, the club-shaped gland, the first gill slit, the mouth and the anus in larvae. FGFEexpression starts in mid-neurula stage embryos in the Hatschek's nephridium anlage. Later on, expression is observed in some neurons and, in the larva, FGFE expression is restricted to several neural tube neurons, to the club-shaped gland and to the gut, except the iliocolonic region. FGFC expression starts at the late neurula stage before the mouth opens in the most anterior endoderm and in the future gut just posterior to the pharyngeal region. In the larva, FGFC is expressed in the pre-oral pit, the endostyle and in the club-shaped gland.

FGF signalling function was assessed using pharmacological treatments with an inhibitor of FGFR (SU5402) at different time points (Bertrand et al., 2011). Inhibiting this pathway before gas- trulation induces the loss of the most anterior somites, whereas the posterior ones form normally. Treatment after the gastrula stage leads to a milder phenotype and all the somites form, although the correct morphogenesis of the notochord is affected. The function of FGF signalling at these stages is likely mediated by the MAPK pathway, as treatments with the MEK1/2 inhibitor U0126 induce the same phenotypes (Bertrand et al., 2011). On the other hand, when embryos are treated at the 8-cell stage with SU5402, gastrulation is strongly affected, while treatment with U0126 has no effect. This result suggests that the early function of the FGF signalling pathway is mediated by the activation of a cytoplasmic cascade that does not involve MAPK. Interestingly, it was shown that FGF signalling does not interact with the retinoic acid pathway during somitogenesis, in contrast to what is known in vertebrates (Bertrand et al., 2015).

\section{Insulin receptor}

Three receptors of the INSR (insulin receptor) subfamily are known in vertebrates: IGF1R (insulin-like growth factor 1 receptor), INSR (insulin receptor) and INSRR (insulin receptor-related receptor) (Brunet et al., 2016). These receptors are characterized by the presence in their ectodomain of two L-domains separated by a furin-like cysteine rich region and followed by three fibronectin type III domains (Adams et al., 2000). Their ligands are the insulin and insulin-like growth factors (IGF) 1 and 2, which are secreted proteins of the insulin-relaxin family that are characterized by the presence of a cystine knot motif (Jin Chan and Steiner, 2000).

In amphioxus, a unique receptor presenting the classical domain organization detailed above has been described (D'Aniello et al., 2008, Pashmforoush et al., 1996). The expression of INSR has so far only been assessed by Northern blot in $B$. californiensis adults transversally cut into four parts (Pashmforoush et al., 1996). The authors showed that transcripts could be detected in all of these four regions.

Two genes, coding for Insulin-like peptides (ILP) were described in the genome of $B$. floridae (Lecroisey et al., 2015) long after the first description of an Ilpgene in B. californiensis (Chan et al., 1990). Both are ohnologues of vertebrate insulin genes IGF1 and IGF2. The embryonic expression pattern of one of them, IIp, was studied in B. lanceolatum (Lecroisey et al., 2015) and in neurulae of $B$. floridae(Holland et al., 1997). The authors showed that expression starts at the gastrula stage in the dorsal paraxial mesendoderm. Then, at the beginning of neurulation, IIp is expressed in the most anterior forming somites and in the posterior endoderm, with a pattern reminiscent of the one observed for Delta at this stage. Expression then becomes restricted to the central endoderm in both species (Holland et al., 1997, Lecroisey et al., 2015). In late larvae prior to mouth opening, IIp transcripts are detected in the dorsal pharyngeal endoderm and in the future gut, just posterior to the pharyngeal region. Finally, in larvae, IIp is expressed in the pharyngeal anterior endoderm and in the club-shaped gland. In adults, IIp (also known as IGF) is expressed in the hindgut and in the hepatic caecum (Guo et al., 2009).

There are no functional data concerning the role of the INSR signalling pathway during embryogenesis. However, the mode of action of INSR and its interaction with ILP or vertebrate ligands has been assessed by several laboratories in vitro or in mammalian cells (Guo et al., 2009, Liu and Zhang, 2011, Pashmforoush et al., 1996). 


\section{Platelet-derived- and vascular endothelial- growth factor receptors}

In vertebrates, there are five receptors of the PDGFR (PlateletDerived Growth Factor Receptor) family, and three of the VEGFR (Vascular Endothelial Growth Factor Receptor) family. Amphioxus possesses a unique receptor related to these two groups of RTKs, named PD/VEGFR. Phylogenetic and synteny conservation analyses suggest that the ancestral VEGFR and PDGFR found in vertebrates arose by tandem duplication of a unique PDNEGFR gene before the two rounds of whole genome duplication (D'Aniello et al., 2008). The amphioxus PD/VEGFR protein shows a domain organization similar to vertebrate VEGFR receptors with seven extracellular immunoglobulin domains (D'Aniello et al., 2008, Suga et al., 1999). During embryonic development, PDNEGFR is first expressed at the neurula stage in two populations of cells of mesodermal origin on both sides of the embryo in the anterior region (Pascual-Anaya et al., 2013). The cells on the left side were proposed to belong to the Hatschek's nephridium anlage, which will form the excretory organ of amphioxus. Before the mouth opens, PD/VEGFR expression is still detected in the forming Hatschek's nephridium as well as in single cells on the right side of the embryo (Pascual-Anaya et al., 2013). At the larval stage, $P D$ NEGFR expression is detected in lateral cells located between the notochord and the gut and below the somites. Labelling is also observed in the anlagen of both the two dorsal aorta branches and the subintestinal vessels, and in the club-shaped gland (PascualAnaya et al., 2013). There are currently no data on genes coding for putative ligands of the amphioxus PD/NEGFR. The embryonic function of the PD/VEGFR signalling pathway was assessed using an inhibitor of the receptor (SU5416) (Pascual-Anaya et al., 2013). Continuous treatment starting at the neurula stage induces a mild but penetrant phenotype with late neurula embryos and larvae presenting a curved posterior region (Pascual-Anaya et al., 2013). The authors showed that this phenotype is associated with a reduction in Laminin immunostaining in the regions of the dorsal aorta and subintestinal vessels, suggesting that the PD/NEGFR pathway is implicated in the formation of the circulatory system in amphioxus (Pascual-Anaya et al., 2013).

\section{Tropomyosin receptor kinase}

Trk (tropomyosin receptor kinase) family members are neurotrophin receptors implicated in neuronal development, plasticity and survival (Lu et al., 2005). Amphioxus possesses a unique receptor ohnologue of vertebrate NTRK1, NTRK2 and NTRK3, and the protein presents a comparable domain organization to its vertebrate counterparts with cysteine-rich clusters, several leucine-rich repeats, and two IgC2 domains in its extracellular region (Benito-Gutierrez et al., 2005). Expression of $B$. floridae Trk is first observed in several epidermal cells in the ventral midline at the early neurula stage. Subsequently, labelling is detected in additional cells located mediolaterally. It has been proposed that these cells may be epidermal sensory neurons of the peripheral nervous system that migrate during embryonic development. At the larva stage, Trk expression is detected in the pre-oral pit and transiently in some anterior cells.

Trk receptors have several ligands in vertebrates, including NGF (Nerve Growth Factor), BDNF (Brain-derived neurotrophic factor), NT-3 (Neurotrophin-3) and NT-4 (Neurotrophin-4), which are secreted proteins. A unique ligand gene has been found in amphioxus (Hallbook et al., 2006) but there is currently no information on its expression pattern. Interestingly, it has been shown that the amphioxus Trk receptor is activated by vertebrate neurotrophins and drives phosphorylation of both Akt and ERK1/2 in mammalian cells (Benito-Gutierrez et al., 2005). However, the cephalochordate Trk is not able to induce PLC $\gamma$ phosphorylation after NGF stimulation in the same context, highlighting possible differences with the vertebrate neurotrophin pathway mode of action (Benito-Gutierrez et al., 2005).

\section{Other actors}

Amphioxus possesses at least one member of each of the gene families coding for proteins implicated in the three main cascades activated by RTK, namely the MAPK, the PLC $\gamma$ and the PI3K pathways (Bertrand et al., 2009). The embryonic expression patterns of two genes from each cascade have so far been assessed in B. lanceolatum (Bertrand et al., 2009). H/K/NRASa, coding for a RAS GTPase implicated in the MAPK cascade, is expressed ubiquitously during early development (Bertrand et al., 2009). Expression then becomes restricted to the notochord and the club-shaped gland anlage. In the larva, expression is detected in the posterior tip of the notochord and in the club-shaped gland. $R A F$, which codes for a MAPKKK, shows a ubiquitous expression pattern at early developmental stages (Bertrand et al., 2009). Later on, expression is observed in the whole mesoderm and endoderm as well as in the cerebral vesicle before the mouth opens. In the larva, similar expression is observed with high levels in the clubshaped gland. PDK and AKT, coding for proteins of the PI3K cascade, are ubiquitously expressed, except in the epidermis, at almost all developmental stages (Bertrand et al., 2009). Within the PLC $\gamma$ cascade, $P K C \alpha / \beta / \gamma$ is expressed ubiquitously at early stages (Bertrand et al., 2009). During neurulation, expression becomes restricted to ventral neurons of the cerebral vesicle and neural tube. In the larva, neural expression is still observed and $P K C \alpha / \beta / \gamma$ transcripts are also detected in the gut, except in the ilio-colonic region, in the club-shaped gland and in the pre-oral pit. Finally, $P K C \gamma$ expression is ubiquitous, although stronger expression is evident at the larva stage in the club-shaped gland and in the gut, again with the exception of the ilio-colonic region (Bertrand et al., 2009). Altogether, these data suggest that RTKs are able to activate only some specific intracellular cascades in particular embryonic regions in which the adequate actors are expressed at a given stage during amphioxus development.

\section{Transforming growth factor $\beta$ pathway}

\section{How does it work?}

The TGF- $\beta$ (Transforming Growth Factor $\beta$ ) signalling pathway plays crucial roles during embryogenesis as well as in cellular processes in adult animals (Derynck and Akhurst, 2007, Kishigami and Mishina, 2005, Massague et al., 2000). TGF- $\beta$ family members are generally secreted and are cleaved into their active form, which contains a cystine knot (Weiss and Attisano, 2012). They bind to heterodimeric complexes composed of homodimers of type I and type Il serine/threonine kinase transmembrane receptors. Fixation of the ligand induces the phosphorylation of the type I receptors by the type II receptors (Fig. 6). This phosphorylation results in the activation of the type I receptors, which subsequently phosphorylate intracellular molecules called Smads (the name is a contrac- 
tion of Sma and Mad (Mothers against decapentaplegic)), which transduce the signal to the nucleus to regulate the transcription of target genes (Weiss and Attisano, 2012) (Fig. 6). Two signalling pathways are distinguished based on which Smad proteins are phophorylated by the activated transmembrane receptors after ligand binding: the BMP (Bone Morphogenetic Protein) signalling pathway, which is mediated by Smad1, -5 and -8; and the TGF- $\beta$ / Nodal/Activin signalling pathway, which utilises Smad2 and 3 in vertebrates (Bragdon et al., 2011, Chin et al., 2004, Massague et al., 2000). Interestingly, besides Smad signalling, it is now well established that other cascades are also activated downstream of TGF- $\beta$ receptors, such as the MAPK cascade, the Rho-like GTPase signalling pathway and the PI3K pathway, indicating that both Smad and non-Smad signalling participate in the final outcome of the cellular response to TGF- $\beta$ proteins (Bragdon et al., 2011, Zhang, 2009).

In addition to the diversity of TGF- $\beta$ ligands and receptors, both BMP and TGF- $\beta$ signalling pathways are regulated at the extracellular level by a cocktail of proteins, including pseudoreceptors and extracellular inhibitors as well as metalloproteinases (Bier and De Robertis, 2015). Pseudoreceptors can interact with TGF- $\beta$ receptors and prevent the formation of active ligand/receptor complexes, whereas extracellular antagonists are able to bind to the ligands and decrease their affinity for their receptors (Balemans and Van Hul, 2002, Chin et al., 2004, Gazzerro and Canalis, 2006). Here we will focus our attention on extracellular regulation of TGF- $\beta$ signalling in amphioxus.

\section{Receptors and extracellular actors in amphioxus}

In the $B$. floridae genome, three type I $(A / k 1 / 2, A / k 3 / 6$ and Alk4/5/7) and three type II ( TGF- $\beta R I I$, ActRII and BMPRII) receptor genes have been identified (Satou et al., 2008), but no expression pattern has been reported yet. However, the expression of the pseudoreceptor $B A M B I$ (BMP and Activin Membrane-Bound
Inhibitor) has been analyzed during early developmental stages. $B A M B /$ transcripts are detected at the gastrula stage in the ventral mesendoderm and, later on during neurulation, in the endoderm (Yu et al., 2007).

Eighteen TGF- $\beta$ genes are present in the $B$. floridae genome (Satou et al., 2008). Among these extracellular ligands, the orthology relationships with vertebrate TGF- $\beta$ family members have been clearly defined by phylogenetic analysis for thirteen of them (Satou et al., 2008). Six genes coding for ligands of the BMP subfamily were identified as $A D M P, B M P 2 / 4, B M P 3 / 3 b, B M P 5-8, B M P 9 / 10$ and $G D F 5 / 6 / 7$, and seven of the TGF- $\beta /$ Nodal/Activin subfamily, namely Lefty, Myostatin, Nodal, TGF- $\beta$, Vg1, and two Activin/Inhibin genes (Satou et al., 2008). Developmental expression patterns have been described in amphioxus for ADMP (Kozmikova et al., 2013, Yu et al., 2007), BMP2/4 (Kozmikova et al., 2013, Panopoulou et al., 1998, Yong et al., 2017, Yu et al., 2007), BMP3/3b (Sun et al., 2010), BMP5-8 (Kozmikova et al., 2013, Yu et al., 2007), Lefty (Morov et al., 2016, Onai et al., 2010, Yu et al., 2007), Nodal (Morov et al., 2016, Onai et al., 2010, Yu et al., 2002, Yu et al., 2007) and Vg1 (Onai et al., 2010).

$A D M P$ is first expressed in the dorsal half of the mesendoderm from the early gastrula stage until the end of gastrulation in $B$. floridae. At the mid-gastrula stage, $A D M P$ starts to be expressed in the neural plate; this expression is maintained until the neurula stage, when transcript detection becomes restricted to the medial part of the plate. At this stage, paraxial mesoderm expression of $A D M P$ is progressively lost but is maintained in the axial mesoderm (Kozmikova et al., 2013, Yu et al., 2007).

From the onset of gastrulation, BMP2/4 and BMP5-8 are coexpressed in the entire mesendoderm until the late gastrula stage, when their expression in the axial mesoderm begins to disappear, concomitantly with the appearance of expression of BMP2/4 in lateral and ventral ectoderm (Kozmikova et al., 2013, Panopoulou et al., 1998, Yu et al., 2007). BMP2/4 expression is then lost in the

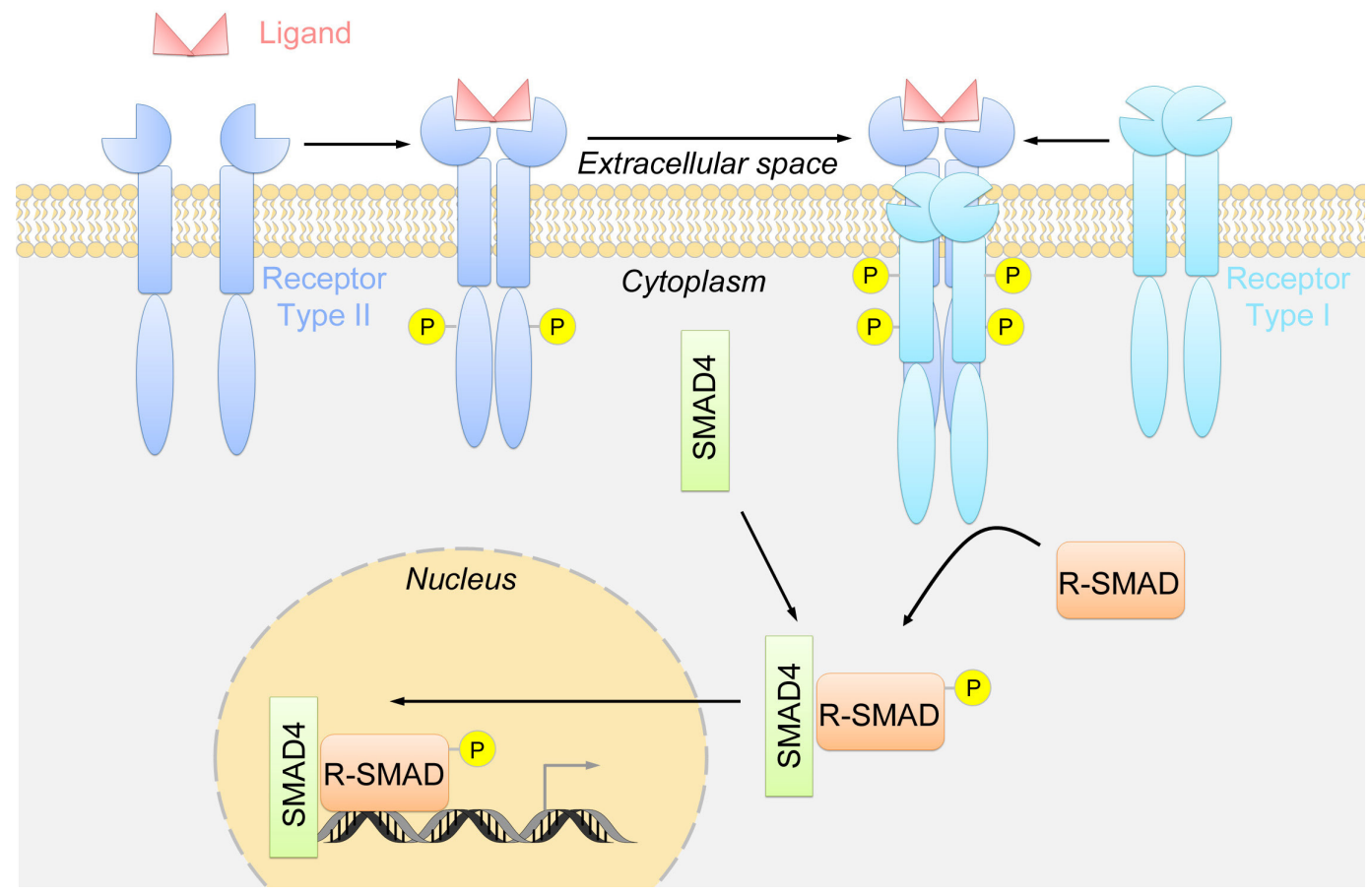

Fig. 6. Simplified schematic view of the canonical transforming growth factor (TGF)- $\beta$ signalling pathway. The binding of ligands to a dimer of type II receptors leads to their phosphorylation. In turn, this dimer interacts with, and phosphorylates, a dimer of type I receptors. Activated type I dimers phosphorylate a regulatory SMAD (R-SMAD), which interacts with SMAD4. The dimer enters the nucleus and activates the transcription of target genes after DNA binding. 
somites during neurulation, except in the tailbud. Expression is also observed in some epidermal cells in front of the neuropore. Within the endodermal derivatives, BMP2/4 is expressed in the pharyngeal region and in the posterior presumptive gut; no expression is detected in the midgut from the neurula stage onwards. At the late neurula stage, BMP2/4 transcripts are detected in the forming club-shaped gland and in the Hatschek's right diverticulum as well as in a row of mesothelial cells on the right along the "ventral midline". In the larva, BMP2/4 expression pattern is quite similar (Panopoulou et al., 1998). No expression data are available for BMP5-8 after the early neurula stage.

$B M P 3 / 3 b$ is expressed during gastrulation in the whole mesendoderm of $B$. japonicum. At the neurula stage, $B M P 3 / 3 b$ is first expressed in the border of the neural plate and in the paraxial mesoderm. Later on, expression is detected in part of the neural plate and in median somites. At the larva stage, $B M P 3 / 3 b$ is expressed in the anterior part of the closed neural tube, in the pharynx, the Hatschek's left diverticulum, the pre-oral ciliated pit, the club-shaped gland and the gill slits (Sun et al., 2010). Expression of $B M P 3 / 3 b$ has also been reported in adult amphioxus, where the $B M P 3 / 3 b$ transcripts are detected in the nerve cord, the sheath surrounding the notochord, the metapleural fold and in the oocytes (Sun et al., 2010).

Nodal, Vg1 and Lefty possess very similar expression pattern during embryonic development in amphioxus. Both Nodaland Vg1 are expressed maternally. $V g 1$ is expressed ubiquitously until the end of the blastula stage, whereas Nodal expression is restricted to the two-thirds of the embryo towards the animal pole. During gastrulation, Nodal, Vg1 and Lefty are expressed in the dorsal ectoderm and mesendoderm, with Lefty expressed in a more axially restricted region (Morov et al., 2016, Onai et al., 2010, Yu et al., 2002, Yu et al., 2007). At the neurula stage, these three genes begin to be expressed only on the left part of the embryo, first in the three most anterior somites and later on in all of the left somites, with stronger expression in the most anterior somites and the posterior forming somites (Onai et al., 2010, Yu et al., 2002, Yu et al., 2007). Nodal is also expressed in the Hatschek's left diverticulum, the lateral ectoderm and endoderm corresponding to the future region where the mouth will open at the late neurula stage (Yu et al., 2002). More detailed expression patterns for Vg1 and Lefty are not available after neurula stage. At the larval stage, Nodal expression is restricted to the most posterior part of the left somitic tissue, expression which disappears in one week old larvae (Yu et al., 2002).

\section{Other actors}

In amphioxus, seven extracellular proteins orthologous to proteins known to exert an antagonist or modulator activity on BMP or TGF- $\beta /$ Nodal/Activin ligands have been identified: Cerberus, Chordin, Gremlin, and NBL1 (Neuroblastoma suppressor of tumorigenicity 1 , also called DAN), Noggin, Tsg (Twisted gastrulation) and Tolloid (also called Xolloid in Xenopus and BMP1 in human). The expression pattern has been described for all the corresponding genes except Noggin.

Cerberus, Gremlin and NBL1 belong to the DAN (Differential screening-selected gene Aberrative in Neuroblastoma) family and present a typical cystine knot structure. Cerberus is first expressed at the gastrula stage in the anterior mesendoderm underlying the presumptive neural plate. At the early neurula stage, Cerberus expression is observed in the first anterior somites before becoming asymmetrical after the loss of expression on the left side. At the mid-neurula stage, Cerberus is no longer expressed in the somites and transcripts are only detected in the ventral part of the closing neural tube. No expression could be detected by in situ hybridization at later stages (Le Petillon et al., 2013, Onai et al., 2010).

Gremlin is first expressed in a small, restricted region of the ventral mesendoderm, expression which remains at the early neurula stage when Gremlin also begins to be expressed in cells along the borders of the neural plate. At the mid-neurula stage, Gremlin is expressed in cells lateral to the neural tube and at the level of the midline of the ventral endoderm. Gremlin expression is also detected at the level of the first left somite in the presumptive Hatschek's nephridium. At the late neurula stage these territories still express Gremlin, which begins to be expressed in the cerebral vesicle. At the larval stage, Gremlin is expressed in some cells of the cerebral vesicle and in cells of the pre-oral pit and endostyle (Le Petillon et al., 2013).

In amphioxus, NBL1 expression has only been detected at the larval stage in the somites and in the club-shaped gland (Le Petillon et al., 2013).

Chordin is one of the first BMP modulator proteins to have been characterized in amphioxus. Interestingly, expression of Chordin is similar to the expression of $A D M P$ in amphioxus. Chordin is first expressed in the dorsal ectoderm and mesendoderm during gastrulation. At the neurula stage, expression is observed in the neural plate and in the axial and paraxial mesoderm before being restricted to the medial part of the closing neural plate and to the axial mesoderm (Somorjai et al., 2008, Yu et al., 2007). Then, before mouth opening, Chordin is expressed in the posterior region of the embryo and in particular neurons. Finally, in the larva, Chordin is expressed in the posterior region, in the club-shaped gland, and in the cerebral vesicle (Somorjai et al., 2008).

Tsg and Tolloid are two proteins known to modulate BMP signalling (Troilo et al., 2016). Tolloid is a zinc metalloproteinase able to cleave Chordin, making it unable to antagonize BMP ligands. Tsg is able to bind either BMP or the BMP/Chordin complex, thereby having antagonistic or agonistic activity. It can also enhance Tolloid cleavage activity on Chordin, decreasing its anti-BMP action. In amphioxus, Tsg begins to be expressed at the early gastrula stage in the dorsal mesendoderm and is expressed during neurula stage in the whole mesoderm (Yu et al., 2007). Tolloid-like is first expressed at the mid-gastrula stage in the ventral mesendoderm and then in the ventral endoderm during neurulation (Yu et al., 2007).

\section{Functional studies}

The main strategy used to modify TGF- $\beta$ signalling during amphioxus development is the use of small molecule inhibitors and recombinant proteins to inhibit or activate TGF- $\beta$ pathways, respectively. Dorsomorphin is used to inhibit BMP type I receptor (Alk3/6) and has been shown to disrupt the nuclear localization of phosphorylated Smad1/5/8 (Kaji et al., 2016, Kozmikova et al., 2013, Lu et al., 2012). SB505124 and SB431542 are two inhibitors of TGF- $\beta$ type I receptors (Alk4/5/7) used to inhibit TGF- $\beta$ / Nodal/Activin pathway (Bertrand et al., 2015, Kaji et al., 2016, Kozmikova et al., 2013, Li et al., 2017, Morov et al., 2016, Onai et al., 2010, Soukup et al., 2015). In contrast, recombinant proteins such as zBMP4 (Lu et al., 2012, Onai et al., 2010, Yu et al., 2008, Yu et al., 2007), hBMP2 (Kozmikova et al., 2013), hActivin (Onai 
et al., 2010) and mNodal (Li et al., 2017) ( $\mathrm{h}=$ human, $\mathrm{m}=$ mouse, $\mathrm{z}=$ zebrafish) have been used to activate TGF- $\beta$ pathways in amphioxus. Due to the technical difficulties involved in microinjecting amphioxus eggs, the use of other tools is still scarce. Nevertheless, injections of mRNA, morpholinos, plasmids or TALENs have also been used to assess the embryonic function of TGF- $\beta$ pathways, as detailed below.

It was first shown using pharmacological treatments that ectopic BMP activation induces the ventralization of the amphioxus embryo, with a loss of expression of dorsal genes and an expansion of ventral gene expression (Kozmikova et al., 2013, Onai et al., 2010, Yu et al., 2008, Yu et al., 2007). In contrast, inhibiting BMP signalling at the blastula stage induces a dorsalization of the embryo with an expansion of the expression of dorsal markers (Kozmikova et al., 2013). On the other hand, earlier inhibition induces the dorsalization of the mesendoderm whereas the ectoderm stays in an uncommitted fate and expresses the pan-ectodermal gene SoxB1a but fails to express epidermal or neural markers. These results strongly suggest that BMP signal inhibition is insufficient for neural induction in amphioxus, but that it is required for epidermal fate acquisition by ectodermal cells (Le Petillon et al., 2017).

Interestingly, the TGF- $\beta /$ Nodal/Activin pathway appears to act in opposition to the BMP signal for axis formation during early development. Indeed, activation of this pathway using recombinant hActivin treatment induces an expansion of dorsal ectodermal and mesodermal gene expression, and a loss of expression of ventral genes (Onai et al., 2010), whereas its repression before gastrulation induces the ventralization of the embryo (Morov et al., 2016, Onai et al., 2010). Moreover, it has been shown that BMP and TGF- $\beta /$ Nodal/Activin signals concomitantly control anteroposterior patterning with an anteriorizing role for the TGF- $\beta /$ Nodal/ Activin signal and a posteriorizing role for the BMP signal (Onai et al., 2010). The authors also analyzed the function of Chordin by injecting corresponding morpholinos. They showed that Chordin knock-down induces a mild phenotype with a loss of anterior marker expression, but to a lesser extent than when the BMP signal was ectopically activated, suggesting that other BMP antagonists might be playing a parallel role in inhibiting BMP signal in the dorsal part of the amphioxus embryo (Onai et al., 2010). In contrast, injection of Cerberus mRNA induces a ventralization and posteriorization similarly to BMP signal activation and the authors therefore suggest that Cerberus might be a TGF- $\beta /$ Nodal/Activin signal antagonist in amphioxus (Onai et al., 2010). It was also recently shown that Nodal/Activin is playing a crucial role for neural induction in amphioxus independently of BMP signal inhibition and that the interactions between both pathways might be tightly regulated in time and space (Le Petillon et al., 2017).

In addition to the role of BMP during antero-posterior and dorsoventral patterning, it has been proposed that the BMP signal might be involved in the formation of epidermal sensory neurons (ESNs) in amphioxus, since manipulating BMP signalling levels affects the distribution of ESNs (Lu et al., 2012). Interestingly, as previously discussed, Delta/notch signalling is implicated in the specification of ESN, and Lu and colleagues showed that BMP signal functions upstream of Delta/Notch to induce/maintain in vivo a ventral neurogenic domain from which the ESNs will derive (Lu et al., 2012). Based on comparative observations with vertebrates, the authors proposed that differences in BMP signal regulation could explain differences in peripheral nervous system formation in the different chordate lineages (Lu et al., 2012).

Nodal signalling is also involved in left/right axis establishment. Based on chemical inhibition of TGF- $\beta$ type I receptors after gastrulation, Soukup and colleagues showed that after inhibition of the TGF- $\beta /$ Nodal/Activin signalling pathway, the left-sided genes are mostly downregulated during early neurula stage and that their expression is later lost. On the other hand, the right-sided genes become symmetrically expressed after such inhibition (Soukup et al., 2015). Consequently, asymmetry of some structures like the pharynx, the somites and the associated neural system, is lost in embryos deprived of Nodal signalling, which present two right sides (Bertrand et al., 2015, Soukup et al., 2015). Recently, these observations were confirmed using transgenic lines of amphioxus with a mutated version of Cerberus, created using the TALEN technique, and using heat shock promoter driving overexpression of several actors of the Nodal pathway such as Cerberus, Nodal, Lefty and Pitx (Li et al., 2017).

A consequence of the loss of asymmetry due to Nodal signal inhibition is the absence of the mouth, which normally forms on the left side of the amphioxus embryo. Indeed, Kaji and colleagues observed that at the level of the left-most anterior somite, a mesovesicle they suggested to be crucial for mouth opening is absent from embryos depleted of Nodal signal after gastrulation (Kaji et al., 2016). The same authors showed that inhibiting the BMP pathway using dorsomorphin impedes mouth opening, suggesting that both Nodal and BMP signals are crucial for this developmental process (Kaji et al., 2016). Conversely, deregulation of endogenous Nodal activity in Cerberus mutants induces the formation of a mouth on both sides of the embryo (Li et al., 2017).

\section{Wnt/ß-catenin pathway}

\section{How does it work?}

Wnt ligands are secreted glycoproteins mediating cell fate decisions, proliferation, and cell movements during embryogenesis across metazoans (Loh et al., 2016). The first Wnt discovered in mouse, named int1 (integration 1) for its oncogenic role (Nusse and Varmus, 1982), was later shown to be homologous to the Wingless $(\mathrm{Wg})$ segment polarity gene in Drosophila. In its simplest form, during $\beta$-catenin dependent or "canonical" signalling, Wnt proteins bind the Frizzled 7-transmembrane domain receptors at the membrane along with LRP5/6 (Low-density lipoprotein receptorrelated protein), thereby recruiting Dishevelled (Fig. 7) (Clevers, 2006). This prevents the scaffolding proteins including APC (Adenomatous polyposis coli) and Axin from assembling the $\beta$-catenin "destruction complex", a large multi-protein assemblage including GSK3 $\beta$ (Glycogen synthase kinase $3 \beta$ ) and CK1 (Caseine kinase 1 ) kinases; $\beta$-catenin is then able to accumulate in the cytoplasm, and free to enter the nucleus, binds TCF (T-cell factor) and other transcriptional partners such as Groucho to mediate downstream signalling events (Fig. 7) (Clevers, 2006). However, in the absence of Wnt ligand, $\beta$-catenin is targeted by the $\beta$-TrCP E3 ubiquitin ligase for ubiquitination, and is degraded by the proteasome (Baron and Kneissel, 2013). This is mediated by assembly of the destruction complex at $\beta$-catenin, and $\mathrm{CK} 1 \alpha$ and GSK3 $\beta$ phosphorylation at key residues in its $\mathrm{N}$-terminus (Clevers, 2006). In the absence of signalling, Axin may also undertake an alternate conformation that blocks its interaction with LRP5/6, but leaves it free to bind $\beta$-catenin to mediate its degradation (Song et al., 2014). 
The Wnt/ $\beta$-catenin pathway is also modulated by a number of co-receptors and extracellular antagonists, including secreted frizzled related proteins (sFRPs), Dickkopf (Dkk) proteins, and Kremens. sFRPs may antagonize signalling in a variety of ways, including via direct interaction with Wnt proteins through their CRD and Netrin domains, or through heterodimerization with Frizzleds, in each case effectively preventing Wnt/Frizzled coupling. Instances in which sFRPs promote pathway activation have also been reported, however, highlighting the importance of cellular context in mediating interactions between possible binding partners (Bovolenta et al., 2008). Dkks in the Dkk1/2/4 class, in contrast, are thought to inhibit Wnt/ $\beta$-catenin by binding directly to the ectodomains of LRP5/6, and thus interfering with Wnt ligand binding (Bao et al., 2012). Kremens are co-receptors for Dkks, and can also bind LRP5/6 in a ternary complex (Zebisch et al., 2016); interestingly, in the presence of Dkk, Kremen proteins enhance Wnt inhibition, while in the absence of Dkk they potentiate LRP5/6 mediated signalling, thus acting as a bi-modal switch during Wnt signalling.

Alternative, "non-canonical" $\beta$-catenin-independent pathways have also been identified, but are poorly understood and much less well characterized in most systems. Some are mediated by Wnt ligands, Frizzled receptors and Dishevelled at the membrane, in addition to other G-protein coupled receptors. Indeed, Dishevelled has been considered to be a branching point between $\beta$-catenin dependent and independent pathways (Gao and Chen, 2010), and it is becoming apparent that such cross-functionality is common (Angers and Moon, 2009). Others utilize alternative receptors, including receptor tyrosine kinases such as ROR or RYK, and do not act positively on $\beta$-catenin mediated transcription in the nucleus, but rather on the actin cytoskeleton, calcium signaling or other nuclear targets (Van Amerongen, 2012). These are collectively known as "Wnt polarity" pathways due to their roles in cellular behavior such as convergence extension or axon guidance (Loh et al., 2016). Given our still limited understanding of how these different pathways are structured, particularly in amphioxus, we focus on a review of members in the context of Wnt/ $\beta$-catenin signalling, with the caveat that many of the upstream components (ligands, receptors etc) described here may be functionally involved in more than one Wnt pathway.

\section{Receptors and ligands in amphioxus}

Wnt ligands are characterized by an N-terminal signal peptide, and $\mathrm{C}$-terminal cysteine residues responsible for the physical interaction with Frizzled receptors. In amphioxus, 12 Wnt genes have been identified corresponding to each of the subfamilies thought to have been present in the bilaterian last common ancestor, with the exception of WntA (reviewed in Albalat and Canestro, 2016). In vertebrates, a number of Wnt duplicates have been retained following the 2 whole genome duplications in the vertebrate ancestor within these subfamilies. Eight amphioxus Wnt ligands were first characterized in B. floridae, including Wnt1, -3, -4, -5, -6, -7, -8 and Wnt11 (Holland et al., 2000, Schubert et al., 2000a, Schubert et al., 2000c, Schubert et al., 2000d, Schubert et al., 2001). Five of these have been partially characterized in B. lanceolatum (Wnt3-Wnt8), and one in $B$. japonicum (Wnt8); their expression shows broad conservation with that seen in the American species (AlbuixechCrespo et al., 2017, Morov et al., 2016, Somorjai et al., 2008).

Wnt 1 is first detected around the lip of the blastopore in gastrulae, and is the most posterior expressed ligand, with expression in the posterior wall of the neurenteric canal in late neurulae (Holland et al., 2000). Qian and colleagues also report that it is maternally expressed by RT-qPCR (Qian et al., 2013).

Wnt3 shows similar blastoporal expression in early gastrulae, but is expressed along the edges of the neural plate by the early

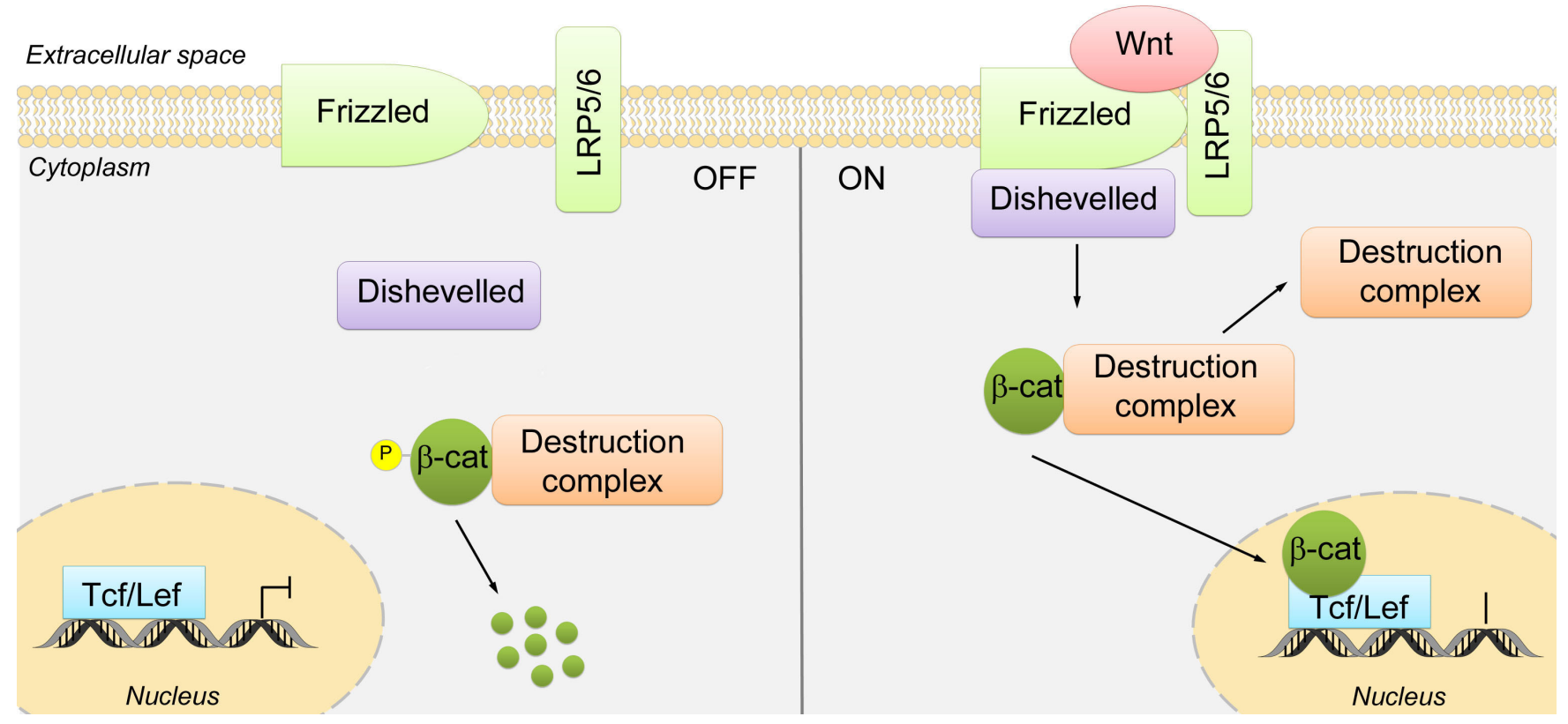

Fig. 7. Simplified schematic view of the Wnt/ $\beta$-catenin signalling pathway. In the absence of Wnt (OFF), $\beta$-catenin ( $\beta$-cat) is phosphorylated by a multi-protein "destruction complex", then ubiquitinated, and, finally, degraded by the proteasome. When a Wnt ligand binds to the receptor Frizzled along with LRP5/6 (ON), Dishevelled is recruited at the membrane. This prevents the formation of the "destruction complex". $\beta$-catenin then accumulates in the cytoplasm and enters the nucleus, where it binds partners such as Tcf/Lef to mediate transcriptional activation of target genes. 
neurula stage except most anteriorly (Schubert et al., 2001). Similar expression is seen in mid-neurulae of $B$. floridaeand $B$. lanceolatum (Albuixech-Crespo etal., 2017, Schubert et al., 2001). As neurulation proceeds, this expression domain resolves to the posterior neural tube and ectoderm, and the posterior wall of the neurenteric canal. In early larvae, Wnt3 can also be detected in the cerebral vesicle, in addition to these domains (Schubert et al., 2001).

In contrast to Wnt3, Wnt4 is expressed throughout the mesendoderm in gastrulae, but most strongly around the blastopore excluding the ectoderm (Schubert et al., 2000b). In neurulae, transcripts are detected in the posterior paraxial mesoderm and hindgut endoderm, but not in the nascent notochord or neural plate; later expression is most notable in the posterior at tailbud level, in the neural tube and cerebral vesicle. In larvae, expression persists in somites, neural tube, hindgut endoderm and posterior cerebral vesicle, in addition to appearing in endostylar endoderm and mesothelial cells near the forming second gill slit (Schubert et al., 2000b).

Wnt5 is expressed in the mesendoderm of the gastrula, but only and very conspicuously around the blastopore, more similarly to Wnt3 (Schubert et al., 2001). By early to mid-neurula stages, expression is strongest in posterior paraxial mesoderm and ventral endoderm in both American and European species (AlbuixechCrespo et al., 2017, Schubert et al., 2001, Somorjai et al., 2008), clearly corresponding to the tailbud by premouth larval stages. Wnt5 is also expressed in the cerebral vesicle and pharynx, resolving to the club-shaped gland in late larvae, as well as the anterior notochord and nascent somite of the tailbud (Schubert et al., 2001).

Wnt6 is maternally expressed (Qian et al., 2013), and as with many other Wnt genes, Wnt6 is expressed around the blastopore in gastrulae. However, Wnt6 is most conspicuously expressed in the CNS in pairs of spots on either edge of the neural plate in early neurulae, as well as in posterior mesoderm (Schubert et al., 2001, Somorjai et al., 2008). In late neurulae, transcripts are detected in the last pair of forming somites, along the length of the neural tube but not in the cerebral vesicle, and in the posterior wall of the neurenteric canal; both the posterior-most neural tube and neurenteric canal expression domains persist in 7-day larvae in B. floridae (Schubert et al., 2001).

Wnt7 has so far not been detected in any stage prior to or including the blastula. In gastrulae, Wnt7 is expressed throughout the mesendoderm, but by early neurula stages is almost entirely restricted to a small central region at the edges of the closing neural tube (Schubert et al., 2000b, Somorjai et al., 2008). In B. lanceolatum mid-neurulae, the anteriormost extension of Wnt7 abuts the posterior boundary of the DiMes (Di-Mesencephalic primordium), thought to be equivalent to the vertebrate Midbrain/ Hindbrain boundary, similarly to Wnt3 (Albuixech-Crespo et al., 2017). As neurulation proceeds, transcripts are detected throughout the neural tube, with the exception of the most posterior parts, but including posterior parts of the cerebral vesicle (Schubert et al., $2000 \mathrm{~b})$. In $90 \mathrm{hpf} B$. floridae larvae, roughly the anterior two-third of the neural tube expresses Wnt7, and expression in the posterior cerebral vesicle persists, with a new domain appearing consisting of a few endodermal cells of the endostyle (Schubert et al., 2000b).

Wnt8 expression in amphioxus is highly dynamic, and is first detected in the early gastrula dorso-laterally in prospective paraxial mesoderm on either side of the archenteron in B.floridae and B.japonicum (Morov et al., 2016, Schubert et al., 2000d). In early neurulae, posterior paraxial mesoderm is strongly labelled, later defining all somites except the first pair, and in a restricted posterior domain of the endoderm that will give rise to the hindgut. In late neurulae of both $B$. floridae and $B$. lanceolatum, transcript expression remains strongest in the posterior mesoderm and endoderm of the growth zone anterior to the tailbud and in several anterior somites posterior to the first pair, but is reduced in intervening somites (Albuixech-Crespo et al., 2017, Schubert et al., 2000d). In 3-day B. floridae larvae, a subset of ventral cells in the cerebral vesicle continues to express Wnt8, but otherwise the gene is downregulated (Schubert et al., 2000d).

In cephalochordates, Wnt11 has only been characterized in $B$. floridae and, besides being maternally expressed (Qian et al., 2013), shows the earliest zygotic expression of the Wnt ligands, with expression in a few cells of the presumptive dorsal side in late blastulae beginning at gastrulation (Schubert et al., 2000a). In neurulae, Wnt11 is expressed in mesodermal myotomes as well as in posterior endodermal and ectodermal domains. By larval stages, most mesodermal expression is lost except in posterior somites, and transcripts can be detected in antero-ventral ectoderm, some ventral mesothelial cells and posterior ectoderm possibly giving rise to the tail fin (Schubert et al., 2000a).

Of the remaining ligands, expression data are still lacking for Wnt2, Wnt9, Wnt10 and Wnt16, but Wnt9 and Wnt10 at least are maternally expressed (Qian et al., 2013). Nothing is known about the role of any Wnt in later larval development, but Wnt5 is also expressed in the undifferentiated blastema during tail regeneration in adult $B$. lanceolatum (Somorjai et al., 2012a).

The Frizzled proteins are G-protein coupled receptors (GPCRs) containing a cysteine-rich domain (CRD). Four Frizzled receptors, $\mathrm{Fz1/2/7,} \mathrm{Fz4,} \mathrm{Fz5/8} \mathrm{and} \mathrm{Fz9/10,} \mathrm{have} \mathrm{been} \mathrm{described} \mathrm{in} \mathrm{the} \mathrm{Asian}$ species B. belcheri (Qian et al., 2013), corresponding to the four subfamilies present in the bilaterian plus cnidarian common ancestor (Schenkelaars et al., 2015). The fifth, Fz3/6, appears to be an innovation of the Olfactores, most closely related to the Fz1/2/7 clade (Schenkelaars et al., 2015). RT-qPCR suggests that all four Frizzled genes are expressed maternally and ubiquitously in the 4-cell stage (Qian et al., 2013). In the early neurula Fz1/2/7 is expressed in the neural plate as well as in somites. The authors suggest that in the larva $F z 1 / 2 / 7$ is expressed in the mouth and the pre-oral pit. Early $F z 1 / 2 / 7$ domains partially overlap with those of $F z 4 . F z 4$ is the only gene clearly expressed in the cerebral vesicle from mid-neurula to larval stages; otherwise it is broadly expressed in mesendoderm, as well as in the pre-oral pit and in components of the pharynx (Qian et al., 2013). Fz5/8 is distinctive in maintaining expression from late gastrula to late larva in the anterior-most ectoderm and endoderm of the embryo (Qian et al., 2013). Finally Fz9/10 has the most posterior expression in the early neurula of all Frizzled genes analysed, showing expression in the posterior neural plate of the mid-neurula stage embryo, and in the last-formed somites (Qian et al., 2013).

\section{Inhibitors/antagonists}

sFRPs are Frizzled Related Proteins that can be secreted due to the replacement of the transmembrane domains with a Netrin domain, and can compete with Frizzled for binding to Wnt ligands. Two have been identified in cephalochordates, and their expression patterns characterized in B. floridae (Yu et al., 2007) and $B$. belcheri (Kong et al., 2012), where they are broadly consistent. $s F R P 1 / 2 / 5$, otherwise named sfrp2-like, is expressed in the 
mesendoderm in gastrulating embryos, later becoming restricted to the anterior mesoderm and endoderm in neurula stages. Kong and colleagues further report that expression becomes undetectable from the late neurula stage onwards in $B$. belcheri (Kong et al., 2012). The second, sFRP3/4, has only been described for early stages in $B$. floridae, where like $s F R P 1 / 2 / 5$ it is expressed in mesendoderm in mid-gastrulae. By late gastrula/early neurula, expression is restricted to a domain around the blastopore, and weakly in the mesoderm.

The first Dickkopf protein, Dkk1, was described in Xenopus, where it was shown to be a potent antagonist of Wnt signalling, and to have head-inducing activity (Glinka et al., 1998). Two antagonists of the Dickkopf family have been described in cephalochordates, corresponding to the two paralogy groups found in vertebrates: Dkk1, -2 and -4 and Dkk3. While Dkk1 -2 and -4 show Wnt antagonizing activity, the role of Dkk3 in Wnt signalling is unclear, but it may potentiate Wnt signalling in some contexts (Nakamura et al., 2007). In B. floridae, Dkk1/2/4 is expressed vegetally in early gastrulae, and most strongly in a mesendodermal ring around the blastopore (Yu et al., 2007). By neurula stages, it is expressed not only at the site of blastopore closure, but also in two clear anterior stripes on either side of the midline in the first two pairs of somites. This expression is similar in B. belcheri until mid-neurula stages, when the posterior domain further resolves into a pair of expression spots in what appear to represent the last formed somites (Zhang and Mao, 2010). Later, expression becomes asymmetric on the left side in tailbud mesoderm, where by premouth larval stages it has disappeared entirely. In larvae, $D k k 1 / 2 / 4$ is only expressed in two anterior left patches in the pharyngeal region, and finally only in the cerebral vesicle of late larvae (Zhang and Mao, 2010).

In amphioxus, Dkk3 possesses an additional TGF- $\beta$ receptor 2 domain in the $\mathrm{N}$-terminus, which is absent in other species (Onai et al., 2012). Dkk3 expression in B. floridae is virtually a mirror image of $D k k 1 / 2 / 4$ at early stages, when it is expressed most strongly in the animal pole, until resolving into a strong anterior ectodermal and an anterior-ventral endodermal domain in neurulae (Yu et al., 2007). Careful sectioning shows that the expression of $D k k 3$ in the anterior endoderm is restricted to the left side, while that in the ectoderm is limited to the anterior end of the neural plate (Onai et al., 2012). Surprisingly, in B. belcheri Dkk3 expression has only been detected in a central patch of the larval gut (Zhang and Mao, 2010), which is difficult to corroborate as data are absent in other cephalochordates for late stages. Taken together with dorsal/ventral expression of BMP ligands and antagonists, the expression of Wnt antagonists such as Dkk1/2/4 and sFRPs anteriorly, along with multiple Wnt ligands posteriorly, suggested the existence of a dorsal organizer in amphioxus as found in vertebrates ( $Y u$ et al., 2007). The presence of such an organizer in amphioxus has indeed recently been confirmed (Le Petillon et al., 2017).

\section{Co-regulators}

In addition to the receptors and antagonists/inhibitors described above, the Wnt/ $\beta$-catenin pathway is regulated by a number of co-receptors extracellularly, including low-density lipoprotein receptor-related proteins (LRP) and Kremen proteins, many of which act through binding Dkks with high affinity. In vertebrates, LRP5 and -6 are orthologous to the single LRP5/6 "Arrow" in Drosophila) found in amphioxus. LRP5/6 expression has been described only in $B$. floridae, and perhaps unsurprisingly given its function, is expressed almost ubiquitously in the mesoderm and endoderm of neurula stage embryos, with the exception of the tailbud (Wang et al., 2016).

In vertebrates, two Kremens have been identified, Kremen1 and Kremen2, with clear roles in potentiating the Wnt inhibitory effects of Dkk1 (Cruciat and Niehrs, 2013) via direct binding in a ternary complex with LRP6 (Zebisch et al., 2016). In the B. floridae genome, four Kremen genes (Krm1, -2, -3, -4) with close affinity and similar domain structure content to vertebrate Kremens 1 and -2 have been localized to the same scaffold, and thus appear to have evolved via tandem duplication (Zhang and Mao, 2010). The authors further identify at least three additional Kremen-like (Krl) proteins, all with alternate domain structures lacking the Kringle domain (Zhang and Mao, 2010). Developmental expression of $B$. belcheri Krm1 and Krm2 has been described (Zhang and Mao, 2010). Krm1 is reportedly expressed throughout the mesendoderm and axial somitic and notochordal mesoderm and dorsal endoderm in neurulae and larvae, respectively. In contrast, Krm2 shows more localized expression in three spots in the pharyngeal region on the left and right sides of larvae. $\mathrm{Krm} 4, \mathrm{Krl1}$ or $\mathrm{Krl3}$ are reported to lack clear developmental expression (Zhang and Mao, 2010).

\section{Cytoplasmic regulators}

In the $B$. floridae genome, a single Dishevelled $(D v l)$ has been identified, and is unusual in being one of the only known Wnt pathway members to be expressed asymmetrically in the animal pole in cleavage stages (Wang et al., 2016). This translates to stronger dorsal expression in gastrula stages. Although broadly expressed in the mesendoderm of neurula stage embryos, at least in early stages there is an apparent antero-posterior gradient. From late neurula to early larval stages, $D v l$ is broadly expressed, but most strongly in the paraxial mesoderm forming the somites (Wang et al., 2016).

Adenomatous polyposis coli (APC) is a tumour suppressor associated with colorectal cancers, and is a key protein of the "destruction complex". Apc expression has been documented in $B$. floridae, where it was found to be ubiquitous in early cleavage stages and blastulae (Wang et al., 2016). Particularly in larval stages, Apc expression is similar to that of $L R P 5 / 6$ in concentrating in anterior neurons of the CNS as well as in the pre-oral pit (Wang et al., 2016).

Three kinases associated with $\beta$-catenin destruction in the absence of Wnt/Fz/LRP signalling have been characterized: GSK3 $\beta$, CK1 $\alpha$ and CK1ס (Wang et al., 2016). GSK3 $\beta$ gene expression in $B$. floridae is broad, occurring almost ubiquitously from early cleavage to larval stages in mesendoderm (Wang et al., 2016). $C K 1 \alpha$ and $C K 1 \delta$ show similar expression until gastrulation, when CK1 $1 \delta$ appears to be more strongly expressed dorsally. Asymmetry in dorsal mesoderm and the neural plate continues for both transcripts throughout neurulation, with an absence of expression most anteriorly. Expression of $C K 1 \alpha$ and $C K 1 \delta$ diverge somewhat in late neurulae, with the most distinct patterns found in larvae (Wang et al., 2016); expression continues to be absent in anterior structures such as the cerebral vesicle, and $C K 1 \delta$ is downregulated except in some pharyngeal structures, possibly representing the club-shaped gland or endostyle (Wang et al., 2016).

Two Axin proteins have been identified in vertebrates, Axin and Axin2/Conductin, both of which may act as scaffolds for the degradation of $\beta$-catenin (Chia and Costantini, 2005). The expression 
of B. floridae Axin has been reported (Beaster-Jones et al., 2008, Wang et al., 2016), and is particularly interesting as vertebrate Axin2 is not only a negative regulator but also a target of Wnt $/ \beta$ catenin signalling (Jho et al., 2002). As for other members of the destruction complex, early expression of Axin is broadly uniform until after the blastula stage (Wang et al., 2016). In gastrulae, Axin is expressed throughout the mesendoderm, but most strongly around forming lips of the blastopore excluding the ectoderm (Beaster-Jones et al., 2008, Wang et al., 2016). By late gastrula/ early neurula stages however, Axin is strongly expressed in the forming posterior growth zone, with no detectable expression in the anterior-ventral mesendoderm (Beaster-Jones et al., 2008, Wang et al., 2016). In late neurulae and larvae, transcripts are detected in the growth zone/forming tailbud (Beaster-Jones et al., 2008, Wang et al., 2016), consistent with expression of many Wnt ligands, as well as possibly in patches in the pharyngeal endoderm (Wang et al., 2016).

\section{Nuclear signalling}

The key effector of $\mathrm{Wnt} / \beta$-catenin in the nucleus is $\beta$-catenin itself. $\beta$-catenin, known by the name Armadillo due to its mutant "naked" cuticle phenotype in Drosophila embryos, consists of an intrinsically disordered $\mathrm{N}$-terminal region, a central Armadillo domain consisting of repeating alpha-helix coiled coils, and a C-terminus containing the transactivation domain. In vertebrates, 9 Armadillo containing proteins within three subfamilies have been identified, of which two $\beta$-catenin orthologues exist: $\beta$-catenin itself, and Plakoglobin ( $\gamma$-catenin) (McCrea and Gottardi, 2016). Surprisingly, the developmental expression of amphioxus' unique $\beta$-catenin has still not been reported. However, the protein has been localized using two different antibodies, one in B. floridae (Holland et al., 2005) and the other in B. belcheri (Oda et al., 2004, Yasui et al., 2002). The first was generated against the $\mathrm{N}$-terminal 173 amino acids of the sea urchin Lytechinus variegatus protein, while the second recognises the $\mathrm{C}$-terminus of vertebrate $\beta$-catenin (Holland et al., 2005, Oda et al., 2004, Yasui et al., 2002). Interestingly, the antibodies have together revealed the transcriptional and adhesive functions predicted for the protein. In particular, in $B$. floridae, the $\mathrm{N}$-terminal antibody localises to the animal pole in early cleavage stages, with clear nuclear localisation in all blastomeres until gastrulation. In gastrulae, nuclear $\beta$-catenin is most evident around the blastopore and then in the ectodermal lips of the neural plate. Nuclear localization is lost in the neural plate itself and dorsal ectoderm, remaining ventro-posteriorly until late neurula stages (Holland et al., 2005). In contrast, the C-terminal antibody clearly shows that $\beta$-catenin is also found in the membranes (Oda et al., 2004), where it colocalizes with amphioxus Cadherin-like proteins at the adherens junction (Oda et al., 2004), but only localizes to nuclei clearly in some early stages (Yasui et al., 2002), and in a distribution that differs somewhat from that seen by Holland and colleagues (Holland et al., 2005). While the antibody used in $B$. floridae is no longer available, that used in $B$. belcheri is commercially available and has been used to assess the cellular structure in B. lanceolatum adult regenerating tails (Somorjai et al., 2012b). Interestingly, $\beta$-catenin appears to be upregulated at the membranes and adherens junctions in the blastema (Somorjai et al., 2012b), similarly to the larval tailbud (Oda et al., 2004), but is also not appreciably detectable in the nucleus. This may either reflect the very low (non-detectable) levels of $\beta$-catenin actually required to mediate nuclear signalling at steady states, or a conformational change in the protein that might mask the epitope when it shuttles into the nucleus.

$\beta$-catenin binds T-cell factor/Lymphoid enhancer-binding factors (TCF/LEF) in the nucleus, in addition to a number of other proteins including CtBP (C-terminal binding protein), to mediate target gene activation or repression in a cell-context specific fashion. In amphioxus, a single Tcf/Lef has been identified; in mammals, four TCF genes exist, TCF1 (or TCF7), TCF2 (or LEF1), TCF3 (or TCF7L1) and TCF4 (and TCF7L2), which have complex spatio-temporal regulation, and which differ in their mode of action. A complete developmental expression profile has been characterized in $B$. floridae (Lin et al., 2006). Cytoplasmic maternal Tcf/Lef localises to the animal pole until gastrulation, at which stage zygotic expression is seen in mesendoderm. Expression is detectable in the anterior end of the neural plate and anterior notochord, as well as in the pharynx, hindgut, and somites in neurulae. The notochord, forming somites and pharynx continue to express Tcf/Lef in early larvae, as well as the tailbud, the ciliated pit, and the cerebral vesicle (Lin et al., 2006). Careful mapping in B. lanceolatum at the 7 somite neurula stage suggests this region marks the basal domain within the rostral and intermediate compartments of a hypothalamo-prethalamic primordium (HyPTh), and thus anterior to the diencephalon sensu stricto (Albuixech-Crespo et al., 2017).

Groucho acts as co-repressor with TCF/LEF, but is directly displaced by $\beta$-catenin upon Wnt/ $\beta$-catenin pathway activation (Daniels and Weis, 2005). Groucho is expressed in B. floridae ubiquitously until the blastula/early gastrula, when it is expressed throughout tissues except the ectoderm. This becomes more predominant on the dorsal side, with an apparent gradient of expression strongest in anterior and dorsal mesendoderm and the neural plate by neurula stages. By the late neurula, expression is absent in the midline, and more prominent in the posterior growth zone, the anterior endoderm, and in the paraxial mesoderm of the somites. By larval stages, expression is reported to decrease, remaining only near the tailbud and in parts of pharynx (Wang et al., 2016).

\section{Functional studies}

Studies of Wnt/ $\beta$-catenin signalling in cephalochordates have predominantly focused on its role in polarity establishment and $A / P$ axis formation. The primary means of addressing this in amphioxus, as in many other organisms, has been through the use of small molecules that target the GSK3 $\beta$ kinase. Inhibition of GSK3 $\beta$ through lithium treatment, the application of BIO, CHIR99021, AIsterpaullone or 1 -Azakenpaullone result in stabilisation of $\beta$-catenin protein, which is then free to enter the nucleus where it binds its transcriptional targets to activate downstream signalling (Kramer et al., 2012). So far, no study has achieved Wnt signalling knockdown by directly targeting ligands or receptors during embryogenesis.

The earliest studies of $\mathrm{Wnt} / \beta$-catenin signalling in amphioxus addressed the role of early polarity establishment using lithium treatments in B. belcheri (Yasui et al., 2002) and B. floridae (Holland et al., 2005). In B. belcheri, treatment after fertilisation results in defects in cleavage and the generation of masses of cells lacking obvious polarity, with "escapers" developing into radially symmetric embryos, but which maintain some dorso-ventral polarity (Yasui et al., 2002). Short pulses of lithium starting at the early blastula stage in $B$. floridae generate exogastrulae, but a slight delay in treatment permits gastrulation and some elongation to occur to 
produce truncated but largely recognizable larvae (Holland et al., 2005). Treatment in both cases results in modified distribution of $\beta$-catenin to the nucleus (Holland et al., 2005, Yasui et al., 2002), and suggests an important conserved role for Wnt/ $\beta$-catenin in A/P polarity establishment in chordates, but not dorsal determination as found in vertebrates (Holland et al., 2005, Yasui et al., 2002).

In addition to its role in early polarity establishment, Wnt/ $\beta$ catenin signalling plays a number of roles during antero-posterior $(\mathrm{A} / \mathrm{P})$ axis extension and patterning, possibly in combination with other pathways. Holland and colleagues (Holland et al., 2005) demonstrated that following the pulse of lithium treatment at the late blastula the treated embryos are significantly more elongated than controls by mid-neurula stages. Although morphologically somewhat amorphous, lithium treatment clearly caused a lack of anterior and neural plate identity (Holland et al., 2005). Combining similar treatments with retinoic acid (RA) or BMS009 (an RA antagonist), Onai and colleagues (Onai et al., 2009) show that Wnt/ $\beta$-catenin and RA have differential effects on A/P patterning, even though phenotypes may appear similar. As expected, lithium caused anterior truncation and posteriorization, with concomitant changes in anterior, neural and posterior marker expression, while RAtreatments often showed more subtle effects, at least until larval stages. In contrast, modulating RA results in dramatic changes in Hox 1 and Hox 3 domains of gene expression, while lithium does not. Interestingly, treatments of $0.75-1.5 \mu \mathrm{M}$ with the more specific GSK3 $\beta$ inhibitor Alsterpaullone are reported to show similar effects to lithium treatment, but with more severe elongation defects (Onai et al., 2009). Nevertheless, taken together, the results indicate a clear effect of Wnt/ $\beta$-catenin on determining posterior identity in amphioxus, but highlight a parallel function of both Wnt and RA signalling in specifying neuronal identity and the hindbrain territory, respectively. Moreover, the results suggest that there may be only limited cross-talk between RA and Wnt/beta-catenin in amphioxus, in contrast to the situation in vertebrates (Onai et al., 2009). Chemical inhibition using two specific GSK3 $\beta$ inhibitors has identified possible downstream targets of Wnt/ $\beta$-catenin signalling both during gastrulation and axis extension (Dailey et al., 2017). Continuous treatment with 1-Azakenpaullone at $10 \mu \mathrm{M}$ from late gastrula onwards results in expansion of the posterior Brachyury2 (Bra2) domain by mid-neurula, as expected if the latter were a bona fide target of Wnt/ $\beta$-catenin signalling, as well as a lack of anterior structures including a pharynx in larvae. This is accompanied by a downregulation of Sp5 in the same domain, an unexpected result given that Sp5 was shown to be activated downstream of canonical Wnt/ $\beta$-catenin signalling (Fujimura et al., 2007, Weidinger et al., 2005). The authors propose that this may be the result of a negative auto-regulatory feedback loop, as other pharmacological treatments result in Sp5 upregulation (Dailey et al., 2017), highlighting the importance of developmental stage and duration of signal modulation in evaluating the role of any given signalling pathway.

In one of few studies in which direct targeting of Wnt pathway components has been achieved, Onai and colleagues show that Dkk3 plays a role in head formation in $B$. floridae, similarly to Dkk1/2/4 members in other systems (Onai et al., 2012). Injection of morpholinos (MO) directed against $D k k 3$ resulted in severe truncations by larval stages, with specific loss of anterior structures including the head and pharynx, concomitant with a reduction in anterior markers. Treatment with $0.5 \mu \mathrm{M}$ of the GSK3 $\beta$ inhibitor $\mathrm{BIO}$ has similar, albeit stronger effects, particularly in posterioriz- ing embryos. Evidence that $D k k 3$ knockdown potentiates the BIO phenotype, combined with experiments in Xenopus animal caps, suggests that Dkk3 plays dual roles in amphioxus: it can inhibit both Wnt/ $\beta$-catenin and Nodal/Vg1 signalling, although the latter is probably not its dominant function and does not appear to be mediated through amphioxus Dkk3's novel TGF- $\beta$ R2 domain (Onai et al., 2012). This study highlights some fundamental differences in the roles of signalling pathways in axis specification between cephalochordates and vertebrates.

The only other study to functionally address components of the Wnt pathway showed that amphioxus sFRP1/2/5 is a likely antagonist of a subset of Wnt proteins using Xenopus luciferase and secondary axis formation assays (Kong et al., 2012). Knockdown and overexpression in amphioxus embryos will be crucial to validate these results.

\section{Conclusions}

Although our knowledge concerning the embryonic functions of different signalling pathways in amphioxus is still incomplete, the analysis of gene expression patterns and the use of pharmacological treatments and other functional techniques already give some insights into the evolution of their function in the chordate lineage. While some signals seem to play a conserved role with those in vertebrates, like RA in antero-posterior patterning, others seem to act differently in each chordate clade in the control of several developmental processes, such as for FGF during somitogenesis or Wnt/ $\beta$-catenin in dorsal determination. More detailed comparisons should help us understand how vertebrates acquired their specific morphological traits, and we believe the development of new genome editing techniques such as TALEN (Transcription Activator-Like Effector Nuclease) or CRISPR-Cas9 (Clustered Regularly Interspaced Short Palindromic Repeats-Cas9 nuclease) (Chen et al., 2014) will open new avenues to better decipher how cells communicate during embryogenesis in amphioxus.

\section{Acknowledgements}

The laboratory of H.E. was supported by the CNRS and the ANR16-CE12-0008-01 and S.B. by the Institut Universitaire de France. The laboratory of I.M.L.S. is currently supported by Wellcome Trust ISSF grant 204821/Z/16/Z.

\section{References}

ADAMS, T.E., EPA, V.C., GARRETT, T.P. and WARD, C.W. (2000). Structure and function of the type 1 insulin-like growth factor receptor. Cell Mol Life Sci57: 1050-1093.

ALBALAT, R. and CANESTRO, C. (2016). Evolution by gene loss. Nat Rev Genet 17: 379-391

ALBUIXECH-CRESPO, B., LOPEZ-BLANCH, L., BURGUERA, D., MAESO, I., SANCHEZ-ARRONES, L., MORENO-BRAVO, J.A., SOMORJAI, I., PASCUALANAYA, J., PUELLES, E., BOVOLENTA, P. et al., (2017). Molecular regionalization of the developing amphioxus neural tube challenges major partitions of the vertebrate brain. PLOS Biol 15: e2001573.

ANDERSEN, P., UOSAKI, H., SHENJE, L.T. and KWON, C. (2012). Non-canonica Notch signaling: emerging role and mechanism. Trends Cell Biol 22: 257-265.

ANGERS, S. and MOON, R.T. (2009). Proximal events in Wnt signal transduction. Nat Rev Mol Cell Biol 10: 468-477.

BALEMANS, W. and VAN HUL, W. (2002). Extracellular regulation of BMP signaling in vertebrates: a cocktail of modulators. Dev Biol 250: 231-250.

BAO, J., ZHENG, J.J. and WU, D. (2012). The structural basis of DKK-mediated inhibition of Wnt/LRP signaling. Sci Signal 5: pe22. 
BARDET, P.L., SCHUBERT, M., HORARD, B., HOLLAND, L.Z., LAUDET, V., HOLLAND, N.D. and VANACKER, J.M. (2005). Expression of estrogen-receptor related receptors in amphioxus and zebrafish: implications for the evolution of posterior brain segmentation at the invertebrate-to-vertebrate transition. Evol Dev7:223-233.

BARON, R. and KNEISSEL, M. (2013). WNT signaling in bone homeostasis and disease: from human mutations to treatments. Nat Med 19: 179-192.

BEASTER-JONES, L., KALTENBACH, S.L., KOOP, D., YUAN, S., CHASTAIN, R. and HOLLAND, L.Z. (2008). Expression of somite segmentation genes in amphioxus: a clock without a wavefront? Dev Genes Evol 218: 599-611.

BENITO-GUTIERREZ, E., NAKE, C., LLOVERA, M., COMELLA, J.X. and GARCIAFERNANDEZ, J. (2005). The single AmphiTrk receptor highlights increased complexity of neurotrophin signalling in vertebrates and suggests an early role in developing sensory neuroepidermal cells. Development 132: 2191-2202.

BENOIT, G., COONEY, A., GIGUERE, V., INGRAHAM, H., LAZAR, M., MUSCAT, G., PERLMANN, T., RENAUD, J.P., SCHWABE, J., SLADEK, F. et al., (2006). International Union of Pharmacology. LXVI. Orphan nuclear receptors. Pharmacol Rev 58: 798-836.

BERTRAND, S., ALDEA, D., OULION, S., SUBIRANA, L., DE LERA, A.R., SOMORJAI, I. and ESCRIVA, H. (2015). Evolution of the Role of RA and FGF Signals in the Control of Somitogenesis in Chordates. PLoS One 10: e0136587.

BERTRAND, S., CAMASSES, A., SOMORJAI, I., BELGACEM, M.R., CHABROL, O., ESCANDE, M.L., PONTAROTTI, P. and ESCRIVA, H. (2011). Amphioxus FGF signaling predicts the acquisition of vertebrate morphological traits. Proc Natl Acad Sci USA 108: 9160-9165.

BERTRAND, S., CAMPO-PAYSAA, F., CAMASSES, A., GARCIA-FERNANDEZ, J. and ESCRIVA, H. (2009). Actors of the tyrosine kinase receptor downstream signaling pathways in amphioxus. Evol Dev 11: 13-26.

BERTRAND, S. and ESCRIVA, H. (2011). Evolutionary crossroads in developmental biology: amphioxus. Development 138: 4819-4830.

BIER, E. and DE ROBERTIS, E.M. (2015). EMBRYO DEVELOPMENT. BMP gradients: A paradigm for morphogen-mediated developmental patterning. Science 348: aaa5838.

BOSNE, S. (2010). The Eph/ephrin gene family in the European Amphioxus an EvoDevo Approach. In Faculdade de ciencias departamento de biologia animal, vol. Mestrado em Biologia Evolutiva e do Desenvolvimento (ed., pp. 46. Lisboa: Universidade de Lisboa.

BOVOlentA, P., ESTEVE, P., RUIZ, J.M., CISNEROS, E. and LOPEZ-RIOS, J. (2008). Beyond Wnt inhibition: new functions of secreted Frizzled-related proteins in development and disease. J Cell Sci 121: 737-746.

BRAGDON, B., MOSEYCHUK, O., SALDANHA, S., KING, D., JULIAN, J. and NOHE, A. (2011). Bone morphogenetic proteins: a critical review. Cell Signal23: 609-620.

BRIDGHAM, J.T., BROWN, J.E., RODRIGUEZ-MARI, A., CATCHEN, J.M. and THORNTON, J.W. (2008). Evolution of a new function by degenerative mutation in cephalochordate steroid receptors. PLoS Genet 4: e1000191.

BRISCOE, J. and THEROND, P.P. (2013). The mechanisms of Hedgehog signalling and its roles in development and disease. Nat Rev Mol Cell Biol 14: 416-429.

BRUCKNER, K., PEREZ, L., CLAUSEN, H. and COHEN, S. (2000). Glycosyltransferase activity of Fringe modulates Notch-Delta interactions. Nature 406: 411-415.

BRUNET, F.G., VOLFF, J.N. and SCHARTL, M. (2016). Whole Genome Duplications Shaped the Receptor Tyrosine Kinase Repertoire of Jawed Vertebrates. Genome Biol Evol 8: 1600-1613.

CALLARD, G.V., TARRANT, A.M., NOVILLO, A., YACCI, P., CIACCIA, L., VAJDA, S., CHUANG, G.Y., KOZAKOV, D., GREYTAK, S.R., SAWYER, S. et al., (2011). Evolutionary origins of the estrogen signaling system: insights from amphioxus. $J$ Steroid Biochem Mol Biol 127: 176-188

CANDIANI, S., MORONTI, L. and PESTARINO, M. (2009). Expression of the orphan nuclear receptor NR4A in a putative adenohypophyseal homologue of amphioxus. Ann NY Acad Sci 1163: 361-364.

CANESTRO, C., POSTLETHWAIT, J.H., GONZALEZ-DUARTE, R. and ALBALAT, R. (2006). Is retinoic acid genetic machinery a chordate innovation? Evol Dev 8: 394-406.

CARVAlHO, J.E., THEOdOSIOU, M., CHEN, J., CHEVRET, P., ALVAREZ, S., DE LERA, A.R., LAUDET, V., CROCE, J.C. and SCHUBERT, M. (2017). Lineagespecific duplication of amphioxus retinoic acid degrading enzymes (CYP26) resulted in sub-functionalization of patterning and homeostatic roles. BMC Evol Biol 17:24.

CASTRO, L.F., SANTOS, M.M. and REIS-HENRIQUES, M.A. (2005). The genomic environment around the Aromatase gene: evolutionary insights. BMCEvolBiol5:43.

CHAN, S.J., CAO, Q.P. and STEINER, D.F. (1990). Evolution of the insulin superfamily: cloning of a hybrid insulin/insulin-like growth factor cDNA from amphioxus. Proc Natl Acad Sci USA 87: 9319-9323.

CHEN, J.K., TAIPALE, J., COOPER, M.K. and BEACHY, P.A. (2002). Inhibition of Hedgehog signaling by direct binding of cyclopamine to Smoothened. Genes \& Development 16: 2743-2748

CHEN, L., TANG, L., XIANG, H., JIN, L., LI, Q., DONG, Y., WANG, W. and ZHANG, G. (2014). Advances in genome editing technology and its promising application in evolutionary and ecological studies. Gigascience 3: 24.

CHIA, I.V. and COSTANTINI, F. (2005). Mouse axin and axin2/conductin proteins are functionally equivalent in vivo. $\mathrm{Mol}$ Cell Biol 25: 4371-4376.

CHIN, D., BOYLE, G.M., PARSONS, P.G. and COMAN, W.B. (2004). What is transforming growth factor-beta (TGF-beta)? Br J Plast Surg 57: 215-221.

CLEVERS, H. (2006). Wnt/beta-Catenin Signaling in Development and Disease. Cell 127: 469-480

CONKLIN, E.G. (1932). The embryology of amphioxus. J. Morphol. 54: 69-151

CRUCIAT, C.M. and NIEHRS, C. (2013). Secreted and transmembrane wnt inhibitors and activators. Cold Spring Harb Perspect Biol 5: a015081.

D'ANIELLO, S., IRIMIA, M., MAESO, I., PASCUAL-ANAYA, J., JIMENEZ-DELGADO, S., BERTRAND, S. and GARCIA-FERNANDEZ, J. (2008). Gene expansion and retention leads to a diverse tyrosine kinase superfamily in amphioxus. $\mathrm{Mol} \mathrm{Biol}$ Evol 25: 1841-1854.

DAILEY, S., KOZMIKOVA, I. and SOMORJAI, I. (2017). Amphioxus Sp5 is a member of a conserved SP complement, and is modulated by Wnt/ $\beta$-catenin signalling. Int J Dev Biol. 61: 723-732.

DANIELS, D.L. and WEIS, W.I. (2005). Beta-catenin directly displaces Groucho/ TLE repressors from Tcf/Lef in Wnt-mediated transcription activation. Nat Struct Mol Biol 12: 364-371.

DELSUC, F., BRINKMANN, H., CHOURROUT, D. and PHILIPPE, H. (2006). Tunicates and not cephalochordates are the closest living relatives of vertebrates. Nature 439: 965-968.

DERYNCK, R. and AKHURST, R.J. (2007). Differentiation plasticity regulated by TGF-beta family proteins in development and disease. Nat Cell Biol 9: 1000-1004

DOVEY, H.F., JOHN, V., ANDERSON, J.P., CHEN, L.Z., DE SAINT ANDRIEU, P. FANG, L.Y., FREEDMAN, S.B., FOLMER, B., GOLDBACH, E., HOLSZTYNSKA, E.J. et al., (2001). Functional gamma-secretase inhibitors reduce beta-amyloid peptide levels in brain. J Neurochem 76: 173-181.

ESCRIVA GARCIA, H., LAUDET, V. and ROBINSON-RECHAVI, M. (2003). Nuclear receptors are markers of animal genome evolution. J Struct Funct Genomics 3 : 177-184.

ESCRIVA, H., BERTRAND, S., GERMAIN, P., ROBINSON-RECHAVI, M., UMBHAUER, M., CARTRY, J., DUFFRAISSE, M., HOLLAND, L., GRONEMEYER, H. and LAUDET, V. (2006). Neofunctionalization in vertebrates: the example of retinoic acid receptors. PLoS Genet 2: e102.

ESCRIVA, H., HOLLAND, N.D., GRONEMEYER, H., LAUDET, V. and HOLLAND, L.Z. (2002). The retinoic acid signaling pathway regulates anterior/posterior patterning in the nerve cord and pharynx of amphioxus, a chordate lacking neural crest. Development 129: 2905-2916.

FONSECA, E., RUIVO, R., LOPES-MARQUES, M.N., ZHANG, H., SANTOS, M.M., VENKATESH, B. and CASTRO, L.F.C. (2017). LXRalpha and LXRbeta Nuclear Receptors Evolved in the Common Ancestor of Gnathostomes. Genome Biol. Evol. 9: 222-230

FUJIMURA, N., VACIK, T., MACHON, O., VLCEK, C., SCALABRIN, S., SPETH, M. DIEP, D., KRAUSS, S. and KOZMIK, Z. (2007). Wnt-mediated down-regulation of Sp1 target genes by a transcriptional repressor Sp5. J Biol Chem 282: 1225-1237.

GAO, C. and CHEN, Y.G. (2010). Dishevelled: The hub of Wnt signaling. Cell Signal 22: 717-727.

GAZAVE, E., LAPEBIE, P., RICHARDS, G.S., BRUNET, F., ERESKOVSKY, A.V., DEGNAN, B.M., BORCHIELLINI, C., VERVOORT, M. and RENARD, E. (2009). Origin and evolution of the Notch signalling pathway: an overview from eukaryotic genomes. BMC Evol Biol 9: 249.

GAZZERRO, E. and CANALIS, E. (2006). Bone morphogenetic proteins and their antagonists. Rev Endocr Metab Disord 7: 51-65

GLINKA, A., WU, W., DELIUS, H., MONAGHAN, A.P., BLUMENSTOCK, C. and 
NIEHRS, C. (1998). Dickkopf-1 is a member of a new family of secreted proteins and functions in head induction. Nature 391: 357-362.

GRONEMEYER, H., GUSTAFSSON, J.A. and LAUDET, V. (2004). Principles for modulation of the nuclear receptor superfamily. Nat Rev Drug Discov 3: 950-964.

GUO, B., ZHANG, S., WANG, S. and LIANG, Y. (2009). Expression, mitogenic activity and regulation by growth hormone of growth hormone/insulin-like growth factor in Branchiostoma belcheri. Cell Tissue Res 338: 67-77.

HALLBOOK, F., WILSON, K., THORNDYKE, M. and OLINSKI, R.P. (2006). Formation and evolution of the chordate neurotrophin and Trk receptor genes. Brain Behav Evol 68: 133-144.

HATSCHEK, B. (1893). The amphioxus and its development. Swan, Sonnenschein \& Company.

HOLLAND, L.Z. and HOLLAND, N.D. (2007). A revised fate map for amphioxus and the evolution of axial patterning in chordates. Integr Comp Biol 47: 360-372.

HOLLAND, L.Z., HOLLAND, N.N. and SCHUBERT, M. (2000). Developmental expression of AmphiWnt1, an amphioxus gene in the Wnt1/wingless subfamily. Dev Genes Evol 210: 522-524.

HOLLAND, L.Z., PANFILIO, K.A., CHASTAIN, R., SCHUBERT, M. and HOLLAND, N.D. (2005). Nuclear beta-catenin promotes non-neural ectoderm and posterior cell fates in amphioxus embryos. Dev Dyn 233: 1430-1443.

HOLLAND, L.Z., RACHED, L.A., TAMME, R., HOLLAND, N.D., KORTSCHAK, D., INOKO, H., SHIINA, T., BURGTORF, C. and LARDELLI, M. (2001). Characterization and developmental expression of the amphioxus homolog of Notch (AmphiNotch): evolutionary conservation of multiple expression domains in amphioxus and vertebrates. Dev Biol 232: 493-507.

HOLLAND, P., PATTON, S., BROOKE, N. and GARCIA- FERNANDEZ, J. (1997). Genetic patterning of the ectoderm and endoderm in amphioxus: From homeobox genes to hormones. SKawashima, S Kikuyama (Eds.), Advances in Comparative Endocrinology: Proceedings of the 13th International Congress on Comparative Endocrinology 247-252.

HOOPER, J.E. and SCOTT, M.P. (1989). The Drosophila patched gene encodes a putative membrane protein required for segmental patterning. Cell 59: 751-765.

HORARD, B., CASTET, A., BARDET, P.L., LAUDET, V., CAVAILLES, V. and VANACKER, J.M. (2004). Dimerization is required for transactivation by estrogenreceptor-related (ERR) orphan receptors: evidence from amphioxus ERR. J Mol Endocrinol 33: 493-509.

JHO, E.H., ZHANG, T., DOMON, C., JOO, C.K., FREUND, J.N. and COSTANTINI, F. (2002). Wnt/beta-catenin/Tcf signaling induces the transcription of Axin2, a negative regulator of the signaling pathway. Mol Cell Biol 22: 1172-1183.

JIN CHAN, S. and STEINER, D.F. (2000). Insulin Through the Ages: Phylogeny of a Growth Promoting and Metabolic Regulatory Hormone1. American Zoologist 40: 213-222.

KAJI, T., REIMER, J.D., MOROV, A.R., KURATANI, S. and YASUI, K. (2016). Amphioxus mouth after dorso-ventral inversion. Zoological Lett 2: 2.

KIDD, S., KELLEY, M.R. and YOUNG, M.W. (1986). Sequence of the notch locus of Drosophila melanogaster: relationship of the encoded protein to mammalian clotting and growth factors. Mol Cell Biol 6: 3094-3108.

KISHIGAMI, S. and MISHINA, Y. (2005). BMP signaling and early embryonic patterning. Cytokine Growth Factor Rev 16: 265-278.

KONG, W., YANG, Y., ZHANG, T., SHI, D.L. and ZHANG, Y. (2012). Characterization of sFRP2-like in amphioxus: insights into the evolutionary conservation of Wnt antagonizing function. Evol Dev 14: 168-177.

KOOP, D., CHEN, J., THEODOSIOU, M., CARVALHO, J.E., ALVAREZ, S., DE LERA, A.R., HOLLAND, L.Z. and SCHUBERT, M. (2014). Roles of retinoic acid and $\mathrm{Tbx} 1 / 10$ in pharyngeal segmentation: amphioxus and the ancestral chordate condition. Evodevo 5: 36

KOOP, D., HOLLAND, L.Z., SETIAMARGA, D., SCHUBERT, M. and HOLLAND, N.D. (2011). Tail regression induced by elevated retinoic acid signaling in amphioxus larvae occurs by tissue remodeling, not cell death. Evol Dev 13: 427-435.

KOOP, D., HOLLAND, N.D., SEMON, M., ALVAREZ, S., DE LERA, A.R., LAUDET, V., HOLLAND, L.Z. and SCHUBERT, M. (2010). Retinoic acid signaling targets Hox genes during the amphioxus gastrula stage: insights into early anterior-posterior patterning of the chordate body plan. Dev Biol 338: 98-106.

KOPAN, R. and ILAGAN, M.X. (2009). The canonical Notch signaling pathway: unfolding the activation mechanism. Cell 137: 216-233.
KOWALEVSKY, A. (1867). Entwicklungsgeschichte des Amphioxus lanceolatus Mem. Akad. St Petersburg.

KOZMIKOVA, I., CANDIANI, S., FABIAN, P., GURSKA, D. and KOZMIK, Z. (2013). Essential role of Bmp signaling and its positive feedback loop in the early cell fate evolution of chordates. Dev Bio/ 382: 538-554.

KRAMER, T., SCHMIDT, B. and LO MONTE, F. (2012). Small-molecule inhibitors of GSK-3: structural insights and their application to Alzheimer's disease models. Int. J. Alzheimer Dis. ePub 2012:381029. (doi: 10.1155/2012/381029)

LANGLOIS, M.C., VANACKER, J.M., HOLLAND, N.D., ESCRIVA, H., QUEVA, C. LAUDET, V. and HOLLAND, L.Z. (2000). Amphicoup-TF, a nuclear orphan receptor of the lancelet Branchiostoma floridae, is implicated in retinoic acid signalling pathways. Dev Genes Evol 210: 471-482.

LE PETILLON, Y., LUXARDI, G., SCERBO, P., CIBOIS, M., LEON, A., SUBIRANA, L., IRIMIA, M., KODJABACHIAN, L., ESCRIVA, H. and BERTRAND, S. (2017). Nodal-Activin pathway is a conserved neural induction signal in chordates. Nature Ecol. Evol. 1: 1192-1200.

LE PETILLON, Y., OULION, S., ESCANDE, M.L., ESCRIVA, H. and BERTRAND, S. (2013). Identification and expression analysis of BMP signaling inhibitors genes of the DAN family in amphioxus. Gene Expr Patterns 13: 377-383.

LECROISEY, C., LAUDET, V. and SCHUBERT, M. (2012). The cephalochordate amphioxus: a key to reveal the secrets of nuclear receptor evolution. Brief Funct Genomics 11: 156-166.

LECROISEY, C., LE PETILLON, Y., ESCRIVA, H., LAMMERT, E. and LAUDET, V. (2015). Identification, evolution and expression of an insulin-like peptide in the cephalochordate Branchiostoma lanceolatum. PLoS One 10: e0119461.

LEE, R.T., ZHAO, Z. and INGHAM, P.W. (2016). Hedgehog signalling. Development 143: 367-372.

LEMMON, M.A. and SCHLESSINGER, J. (2010). Cell signaling by receptor tyrosine kinases. Cell 141: 1117-1134.

LI, G., LIU, X., XING, C., ZHANG, H., SHIMELD, S.M. and WANG, Y. (2017). CerberusNodal-Lefty-Pitx signaling cascade controls left-right asymmetry in amphioxus. Proc Natl Acad Sci USA 114: 3684-3689.

LIN, H.C., HOLLAND, L.Z. and HOLLAND, N.D. (2006). Expression of the AmphiTc gene in amphioxus: insights into the evolution of the TCF/LEF gene family during vertebrate evolution. Dev Dyn 235: 3396-3403.

LIN, Y., CAI, Z., HUANG, S., YANG, L., WANG, C., LIU, Z., CAO, J., AN, Y. and ZHANG, H. (2009). Ptc, Smo, Sufu, and the Hedgehog signaling pathway in amphioxus. Evol Dev 11: 710-718.

LIU, M. and ZHANG, S. (2011). Amphioxus IGF-like peptide induces mouse muscle cell development via binding to IGF receptors and activating MAPK and PI3K/ Akt signaling pathways. Mol Cell Endocrinol 343: 45-54.

LOH, K.M., VAN AMERONGEN, R. and NUSSE, R. (2016). Generating Cellular Diversity and Spatial Form: Wnt Signaling and the Evolution of Multicellular Animals. Dev Cell 38: 643-655.

LU, B., PANG, P.T. and WOO, N.H. (2005). The yin and yang of neurotrophin action. Nat Rev Neurosci 6: 603-614.

LU, T.M., LUO, Y.J. and YU, J.K. (2012). BMP and Delta/Notch signaling control the development of amphioxus epidermal sensory neurons: insights into the evolution of the peripheral sensory system. Development 139: 2020-2030

MASSAGUE, J., BLAIN, S.W. and LO, R.S. (2000). TGFbeta signaling in growth control, cancer, and heritable disorders. Cell 103: 295-309.

MAZET, F. and SHIMELD, S.M. (2003). Characterisation of an amphioxus Fringe gene and the evolution of the vertebrate segmentation clock. Dev Genes Evol 213: 505-509

MCCREA, P.D. and GOTTARDI, C.J. (2016). Beyond beta-catenin: prospects for a larger catenin network in the nucleus. Nat Rev Mol Cell Biol 17: 55-64.

MELLOTT, D.O. and BURKE, R.D. (2008). The molecular phylogeny of eph receptors and ephrin ligands. BMC Cell Biol 9: 27.

MEULEMANS, D. and BRONNER-FRASER, M. (2007). Insights from amphioxus into the evolution of vertebrate cartilage. PLoS One 2: e787.

MIZUTA, T. and KUBOKAWA, K. (2007). Presence of sex steroids and cytochrome P450 genes in amphioxus. Endocrinology 148: 3554-3565.

MOLONEY, D.J., PANIN, V.M., JOHNSTON, S.H., CHEN, J., SHAO, L., WILSON R., WANG, Y., STANLEY, P., IRVINE, K.D., HALTIWANGER, R.S. et al., (2000). Fringe is a glycosyltransferase that modifies Notch. Nature 406: 369-375. 
MOROV, A.R., UKIZINTAMBARA, T., SABIROV, R.M. and YASUI, K. (2016). Acquisition of the dorsal structures in chordate amphioxus. Open Biol 6.

NAKAMURA, R.E., HUNTER, D.D., YI, H., BRUNKEN, W.J. and HACKAM, A.S. (2007). Identification of two novel activities of the Wnt signaling regulator Dickkopf 3 and characterization of its expression in the mouse retina. BMC Cell Biol 8: 52.

NAKANO, Y., GUERRERO, I., HIDALGO, A., TAYLOR, A., WHITTLE, J.R. and INGHAM, P.W. (1989). A protein with several possible membrane-spanning domains encoded by the Drosophila segment polarity gene patched. Nature 341: 508-513.

NUSSE, R. and VARMUS, H.E. (1982). Many tumors induced by the mouse mammary tumor virus contain a provirus integrated in the same region of the host genome. Cell 31: 99-109.

NUSSLEIN-VOLHARD, C. and WIESCHAUS, E. (1980). Mutations affecting segment number and polarity in Drosophila. Nature 287: 795-801.

ODA, H., AKIYAMA-ODA, Y. and ZHANG, S. (2004). Two classic cadherin-related molecules with no cadherin extracellular repeats in the cephalochordate amphioxus: distinct adhesive specificities and possible involvement in the development of multicell-layered structures. J Cell Sci 117: 2757-2767.

ONAI, T., ARAMAKI, T., INOMATA, H., HIRAI, T. and KURATANI, S. (2015). On the origin of vertebrate somites. Zoological Lett 1: 33.

ONAI, T., LIN, H.C., SCHUBERT, M., KOOP, D., OSBORNE, P.W., ALVAREZ, S., ALVAREZ, R., HOLLAND, N.D. and HOLLAND, L.Z. (2009). Retinoic acid and Wnt/ beta-catenin have complementary roles in anterior/posterior patterning embryos of the basal chordate amphioxus. Dev Biol 332: 223-233.

ONAI, T., TAKAI, A., SETIAMARGA, D.H. and HOLLAND, L.Z. (2012). Essential role of Dkk3 for head formation by inhibiting Wnt/beta-catenin and Nodal/Vg1 signaling pathways in the basal chordate amphioxus. Evol Dev 14: 338-350.

ONAI, T., YU, J.K., BLITZ, I.L., CHO, K.W. and HOLLAND, L.Z. (2010). Opposing Nodal/Vg1 and BMP signals mediate axial patterning in embryos of the basal chordate amphioxus. Dev Biol 344: 377-389.

OULION, S., BERTRAND, S. and ESCRIVA, H. (2012). Evolution of the FGF Gene Family. Int J Evol Biol 2012: 298147.

PANOPOULOU, G.D., CLARK, M.D., HOLLAND, L.Z., LEHRACH, H. and HOLLAND, N.D. (1998). AmphiBMP2/4, an amphioxus bone morphogenetic protein closely related to Drosophila decapentaplegic and vertebrate BMP2 and BMP4: insights into evolution of dorsoventral axis specification. Dev Dyn 213: 130-139.

PARIS, M., ESCRIVA, H., SCHUBERT, M., BRUNET, F., BRTKO, J., CIESIELSKI, F., ROECKLIN, D., VIVAT-HANNAH, V., JAMIN, E.L., CRAVEDI, J.P. et al., (2008a). Amphioxus postembryonic development reveals the homology of chordate metamorphosis. Curr Biol 18: 825-830.

PARIS, M., PETTERSSON, K., SCHUBERT, M., BERTRAND, S., PONGRATZ, I., ESCRIVA, H. and LAUDET, V. (2008b). An amphioxus orthologue of the estrogen receptor that does not bind estradiol: insights into estrogen receptor evolution. BMC Evol Biol 8: 219.

PASCUAL-ANAYA, J., ALBUIXECH-CRESPO, B., SOMORJAI, I.M., CARMONA, R., OISI, Y., ALVAREZ, S., KURATANI, S., MUNOZ-CHAPULI, R. and GARCIAFERNANDEZ, J. (2013). The evolutionary origins of chordate hematopoiesis and vertebrate endothelia. Dev Biol 375: 182-192.

PASHMFOROUSH, M., CHAN, S.J. and STEINER, D.F. (1996). Structure and expression of the insulin-like peptide receptor from amphioxus. Mol Endocrinol10:857-866.

QIAN, G., LI, G., CHEN, X. and WANG, Y. (2013). Characterization and embryonic expression of four amphioxus Frizzled genes with important functions during early embryogenesis. Gene Expr Patterns 13: 445-453.

RASMUSSEN, S.L., HOLLAND, L.Z., SCHUBERT, M., BEASTER-JONES, L. and HOLLAND, N.D. (2007). Amphioxus AmphiDelta: evolution of Delta protein structure, segmentation, and neurogenesis. Genesis 45: 113-122.

ROBINSON-RECHAVI, M., ESCRIVA GARCIA, H. and LAUDET, V. (2003). The nuclear receptor superfamily. J Cell Sci 116: 585-586.

SATOU, Y., WADA, S., SASAKURA, Y. and SATOH, N. (2008). Regulatory genes in the ancestral chordate genomes. Dev Genes Evol 218: 715-721.

SCHENKELAARS, Q., FIERRO-CONSTAIN, L., RENARD, E., HILL, A.L. and BORCHIELLINI, C. (2015). Insights into Frizzled evolution and new perspectives. Evol Dev 17: 160-169.

SCHUBERT, M., BRUNET, F., PARIS, M., BERTRAND, S., BENOIT, G. and LAUDET, V. (2008). Nuclear hormone receptor signaling in amphioxus. Dev Genes Evol 218: $651-665$.
SCHUBERT, M., HOLLAND, L.Z. and HOLLAND, N.D. (2000a). Characterization of an amphioxus wnt gene, AmphiWnt11, with possible roles in myogenesis and tail outgrowth. Genesis 27: 1-5.

SCHUBERT, M., HOLLAND, L.Z. and HOLLAND, N.D. (2000b). Characterization of two amphioxus Wnt genes (AmphiWnt4 and AmphiWnt7b) with early expression in the developing central nervous system. Dev Dyn 217: 205-215.

SCHUBERT, M., HOLLAND, L.Z., HOLLAND, N.D. and JACOBS, D.K. (2000c). A phylogenetic tree of the Wnt genes based on all available full-length sequences, including five from the cephalochordate amphioxus. Mol Biol Evol 17: 1896-1903.

SCHUBERT, M., HOLLAND, L.Z., PANOPOULOU, G.D., LEHRACH, H. and HOLLAND, N.D. (2000d). Characterization of amphioxus AmphiWnt8: insights into the evolution of patterning of the embryonic dorsoventral axis. Evol Dev 2: 85-92.

SCHUBERT, M., HOLLAND, L.Z., STOKES, M.D. and HOLLAND, N.D. (2001). Three amphioxus Wnt genes (AmphiWnt3, AmphiWnt5, and AmphiWnt6) associated with the tail bud: the evolution of somitogenesis in chordates. Dev Biol 240: 262-273.

SCHUBERT, M., HOLLAND, N.D., ESCRIVA, H., HOLLAND, L.Z. and LAUDET, V. (2004). Retinoic acid influences anteroposterior positioning of epidermal sensory neurons and their gene expression in a developing chordate (amphioxus). Proc Natl Acad Sci USA 101: 10320-10325.

SCHUBERT, M., HOLLAND, N.D., LAUDET, V. and HOLLAND, L.Z. (2006). A retinoic acid-Hox hierarchy controls both anterior/posterior patterning and neuronal specification in the developing central nervous system of the cephalochordate amphioxus. Dev Biol 296: 190-202.

SCHUBERT, M., YU, J.K., HOLLAND, N.D., ESCRIVA, H., LAUDET, V. and HOLLAND, L.Z. (2005). Retinoic acid signaling acts via Hox1 to establish the posterior limit of the pharynx in the chordate amphioxus. Development 132: 61-73.

SHIMELD, S.M. (1999). The evolution of the hedgehog gene family in chordates: insights from amphioxus hedgehog. Dev Genes Evol 209: 40-47.

SHIMELD, S.M., VAN DEN HEUVEL, M., DAWBER, R. and BRISCOE, J. (2007). An amphioxus Gli gene reveals conservation of midline patterning and the evolution of hedgehog signalling diversity in chordates. PLoS One 2: e864.

SINHA, S. and CHEN, J.K. (2006). Purmorphamine activates the Hedgehog pathway by targeting Smoothened. Nat Chem Biol 2: 29-30.

SOBREIRA, T.J., MARLETAZ, F., SIMOES-COSTA, M., SCHECHTMAN, D., PEREIRA, A.C., BRUNET, F., SWEENEY, S., PANI, A., ARONOWICZ, J., LOWE, C.J. et al., (2011). Structural shifts of aldehyde dehydrogenase enzymes were instrumental for the early evolution of retinoid-dependent axial patterning in metazoans. Proc Natl Acad Sci USA 108: 226-231.

SOMORJAI, I., BERTRAND, S., CAMASSES, A., HAGUENAUER, A. and ESCRIVA $H$. (2008). Evidence for stasis and not genetic piracy in developmental expression patterns of Branchiostoma lanceolatum and Branchiostoma floridae, two amphioxus species that have evolved independently over the course of $200 \mathrm{Myr}$. Dev Genes Evol 218: 703-713.

SOMORJAI, I.M., ESCRIVA, H. and GARCIA-FERNANDEZ, J. (2012a). Amphioxus makes the cut-Again. Commun Integr Biol 5: 499-502.

SOMORJAI, I.M., SOMORJAI, R.L., GARCIA-FERNANDEZ, J. and ESCRIVA, H. (2012b). Vertebrate-like regeneration in the invertebrate chordate amphioxus. Proc Natl Acad Sci USA 109: 517-522.

SONG, X., WANG, S. and LI, L. (2014). New insights into the regulation of Axin function in canonical Wnt signaling pathway. Protein Cell 5: 186-193.

SOUKUP, V., YONG, L.W., LU, T.M., HUANG, S.W., KOZMIK, Z. and YU, J.K. (2015). The Nodal signaling pathway controls left-right asymmetric development in amphioxus. Evodevo 6: 5.

SUGA, H., HOSHIYAMA, D., KURAKU, S., KATOH, K., KUBOKAWA, K. and MIYATA T. (1999). Protein tyrosine kinase cDNAs from amphioxus, hagfish, and lamprey: isoform duplications around the divergence of cyclostomes and gnathostomes. $J \mathrm{Mol}$ Evol 49: 601-608.

SUN, Y., ZHANG, Q.J., ZHONG, J. and WANG, Y.Q. (2010). Characterization and expression of AmphiBMP3 /3b gene in amphioxus Branchiostoma japonicum. Dev Growth Differ 52: 157-167.

TOCCHINI-VALENTINI, G.D., ROCHEL, N., ESCRIVA, H., GERMAIN, P., PELUSOILTIS, C., PARIS, M., SANGLIER-CIANFERANI, S., VAN DORSSELAER, A. MORAS, D. and LAUDET, V. (2009). Structural and functional insights into the ligand-binding domain of a nonduplicated retinoid $X$ nuclear receptor from the invertebrate chordate amphioxus. J Biol Chem 284: 1938-1948.

TROILO, H., BAYLEY, C.P., BARRETT, A.L., LOCKHART-CAIRNS, M.P., JOWITT, 


\section{S. Bertrand et al.}

T.A. and BALDOCK, C. (2016). Mammalian tolloid proteinases: role in growth factor signalling. FEBS Lett 590: 2398-2407.

VAN AMERONGEN, R.E. (2012). Alternative Wnt pathways and receptors. Cold Spring Harbor perspectives in biology 4: a007914.

WANG, H., LI, G. and WANG, Y. (2015). Generating amphioxus Hedgehog knockout mutants and phenotype analysis. Hereditas 10: 010

WANG, J., LI, G., QIAN, G.H., HUA, J.H. and WANG, Y.Q. (2016). Expression analysis of eight amphioxus genes involved in the Wnt/beta-catenin signaling pathway. Dongwuxue Yanjiu 37: 136-143.

WANG, M.M. (2011). Notch signaling and Notch signaling modifiers. Int J Biochem Cell Biol 43: 1550-1562.

WEIDINGER, G., THORPE, C.J., WUENNENBERG-STAPLETON, K., NGAI, J. and MOON, R.T. (2005). The Sp1-related transcription factors sp5 and sp5-like act downstream of Wnt/beta-catenin signaling in mesoderm and neuroectoderm patterning. Curr Biol 15: 489-500.

WEISS, A. and ATTISANO, L. (2012). The TGFbeta superfamily signaling pathway. Wiley Interdiscip Rev Dev Biol 2: 47-63.

WHARTON, K.A., JOHANSEN, K.M., XU, T. and ARTAVANIS-TSAKONAS, S. (1985). Nucleotide sequence from the neurogenic locus notch implies a gene product that shares homology with proteins containing EGF-like repeats. Cell 43: 567-581.

WICHT, H. and LACALLI, T.C. (2005). The nervous system of amphioxus: structure, development, and evolutionary significance. Canadian J. Zool. 83: 122-150.

YASUI, K., LI, G., WANG, Y., SAIGA, H., ZHANG, P. and AIZAWA, S. (2002). beta-
Catenin in early development of the lancelet embryo indicates specific determination of embryonic polarity. Dev Growth Differ 44: 467-475

YONG, L.W., BERTRAND, S., YU, J.K., ESCRIVA, H. and HOLLAND, N.D. (2017) Conservation of BMP2/4 expression patterns within the clade Branchiostoma (amphioxus): Resolving interspecific discrepancies. Gene Expr Patterns 25-26: 71-75.

YU, J.K., HOLLAND, L.Z. and HOLLAND, N.D. (2002). An amphioxus nodal gene (AmphiNodal) with early symmetrical expression in the organizer and mesoderm and later asymmetrical expression associated with left-right axis formation. Evol Dev 4: 418-425.

YU, J.K., MEULEMANS, D., MCKEOWN, S.J. and BRONNER-FRASER, M. (2008). Insights from the amphioxus genome on the origin of vertebrate neural crest. Genome Res 18: 1127-1132.

YU, J.K., SATOU, Y., HOLLAND, N.D., SHIN, I.T., KOHARA, Y., SATOH, N., BRONNERFRASER, M. and HOLLAND, L.Z. (2007). Axial patterning in cephalochordates and the evolution of the organizer. Nature 445: 613-617.

ZEBISCH, M., JACKSON, V.A., ZHAO, Y. and JONES, E.Y. (2016). Structure of the dual-mode Wnt regulator Kremen1 and insight into ternary complex formation with LRP6 and Dickkopf. Structure 24: 1599-1605

ZHANG, Y. and MAO, B. (2010). Embryonic expression and evolutionary analysis of the amphioxus Dickkopf and Kremen family genes. J Genet Genomics37:637-645.

ZHANG, Y., MAO, B., ZHANG, S. and ZHANG, H. (2002). Hedgehog gene in Qingdao amphioxus Branchiostoma belcheri tsingtauense: cloning and expression pattern in early development. J. Marine Biol. Assoc (UK) 82: 629-633.

ZHANG, Y.E. (2009). Non-Smad pathways in TGF-beta signaling. Cell Res 19: 128-139. 


\section{Further Related Reading, published previously in the Int. J. Dev. Biol.}

From the American to the European amphioxus: towards experimental Evo-Devo at the origin of chordates Jordi Garcia-Fernàndez, Senda Jiménez-Delgado, Juan Pascual-Anaya, Ignacio Maeso, Manuel Irimia, Carolina Minguillón, Èlia BenitoGutiérrez, Josep Gardenyes, Stéphanie Bertrand and Salvatore D’Aniello Int. J. Dev. Biol. (2009) 53: 1359-1366 https://doi.org/10.1387/ijdb.072436jg

Evolution of CUT class homeobox genes: insights from the genome of the amphioxus, Branchiostoma floridae Naohito Takatori and Hidetoshi Saiga Int. J. Dev. Biol. (2008) 52: 969-977 https://doi.org/10.1387/ijdb.072541nt

Peter Holland, homeobox genes and the developmental basis of animal diversity Sebastian M. Shimeld Int. J. Dev. Biol. (2008) 52: 3-7 https://doi.org/10.1387/ijdb.072394ss

Developmental expression of the High Mobility Group B gene in the amphioxus, Branchiostoma belcheri tsingtauense

Xiangwei Huang, Lifeng Wang and Hongwei Zhang

Int. J. Dev. Biol. (2005) 49: 49-46

http://www.intjdevbiol.com/web/paper/041915xh

Cell morphology in amphioxus nerve cord may reflect the time course of cell differentiation T C Lacalli

Int. J. Dev. Biol. (2000) 44: 903-906

http://www.intjdevbiol.com/web/paper/11206331

Embryonic development of heads, skeletons and amphioxus: Edwin S. Goodrich revisited P W Holland

Int. J. Dev. Biol. (2000) 44: 29-34

http://www.intjdevbiol.com/web/paper/10761843

Amphioxus Hox genes: insights into evolution and development $\mathrm{J}$ Garcia-Fernàndez and $\mathrm{P}$ W Holland Int. J. Dev. Biol. (1996) 40: S71-S72 http://www.intjdevbiol.com/web/paper/9087701

5 yr ISI Impact Factor $(2013)=2.879$

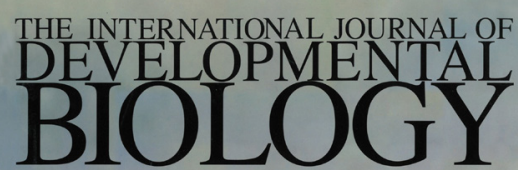

Volume 47 Nos. $7 / 8$ Special Issue

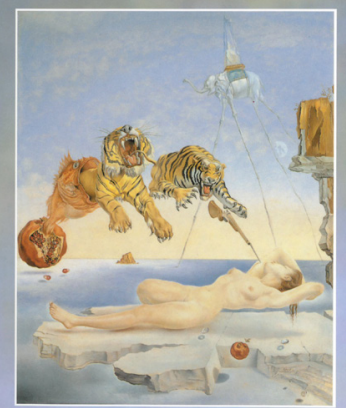

Evolution \& Development
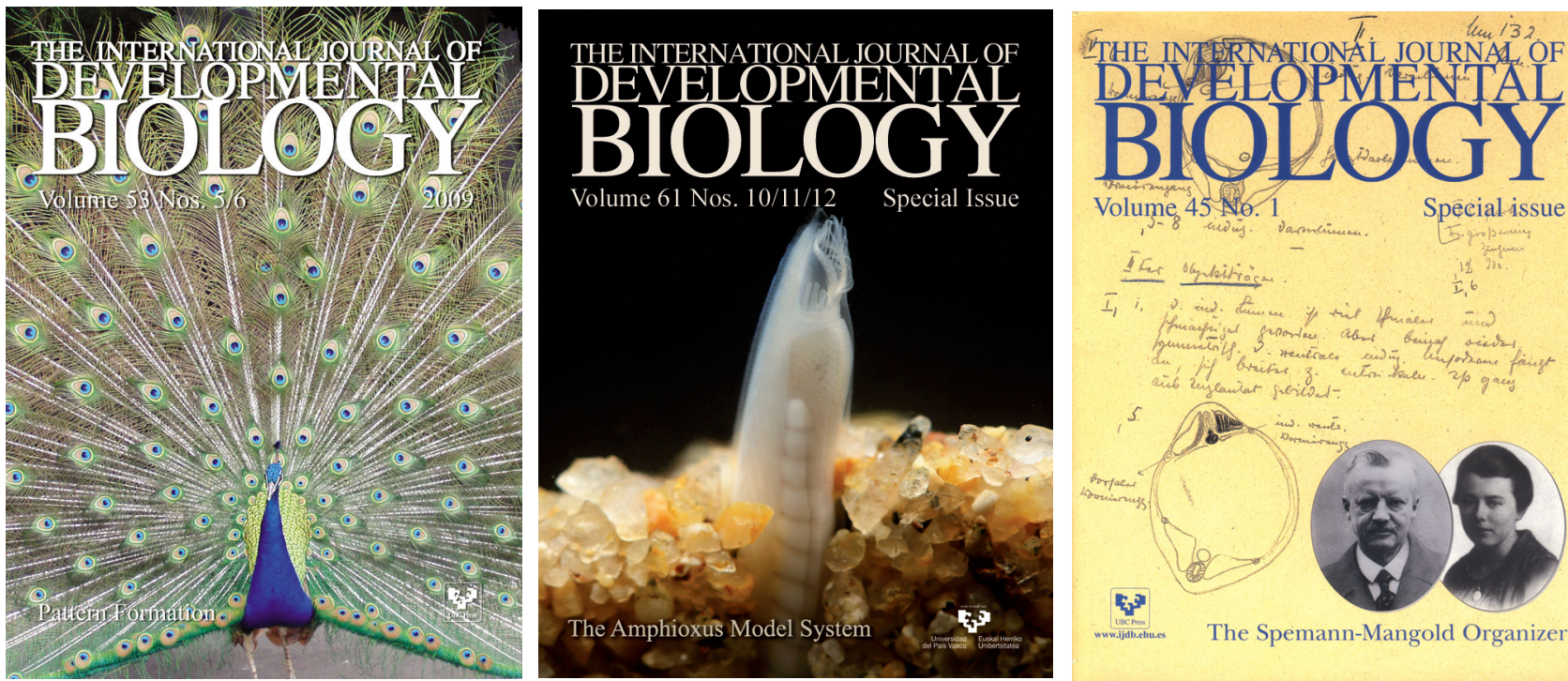

Volume 45 NO. 1

Special issue

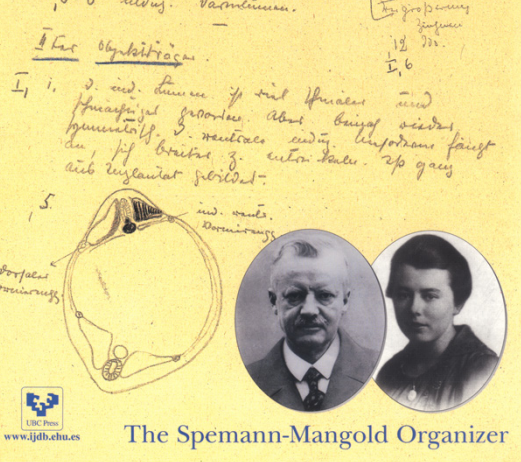

